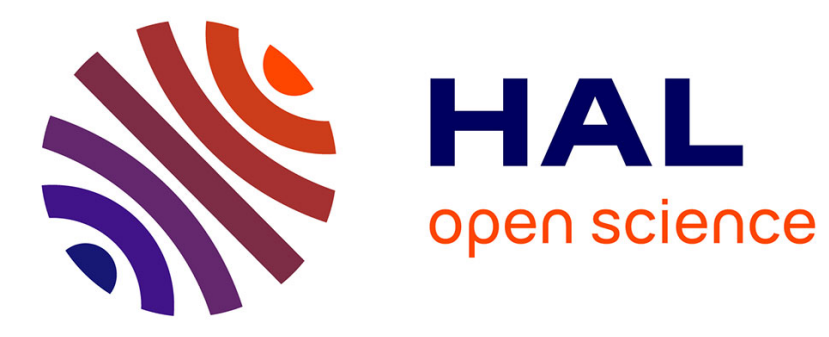

\title{
From large-scale to micro machining: a review of force prediction models
}

\author{
Dimitri Germain, Guillaume Fromentin, Gérard Poulachon, Stephanie \\ Bissey-Breton
}

\section{- To cite this version:}

Dimitri Germain, Guillaume Fromentin, Gérard Poulachon, Stephanie Bissey-Breton. From largescale to micro machining: a review of force prediction models. Journal of Manufacturing Processes, 2013, 15, pp.389-401. hal-00873860

\section{HAL Id: hal-00873860 https://hal.science/hal-00873860}

Submitted on 21 Oct 2013

HAL is a multi-disciplinary open access archive for the deposit and dissemination of scientific research documents, whether they are published or not. The documents may come from teaching and research institutions in France or abroad, or from public or private research centers.
L'archive ouverte pluridisciplinaire HAL, est destinée au dépôt et à la diffusion de documents scientifiques de niveau recherche, publiés ou non, émanant des établissements d'enseignement et de recherche français ou étrangers, des laboratoires publics ou privés. 


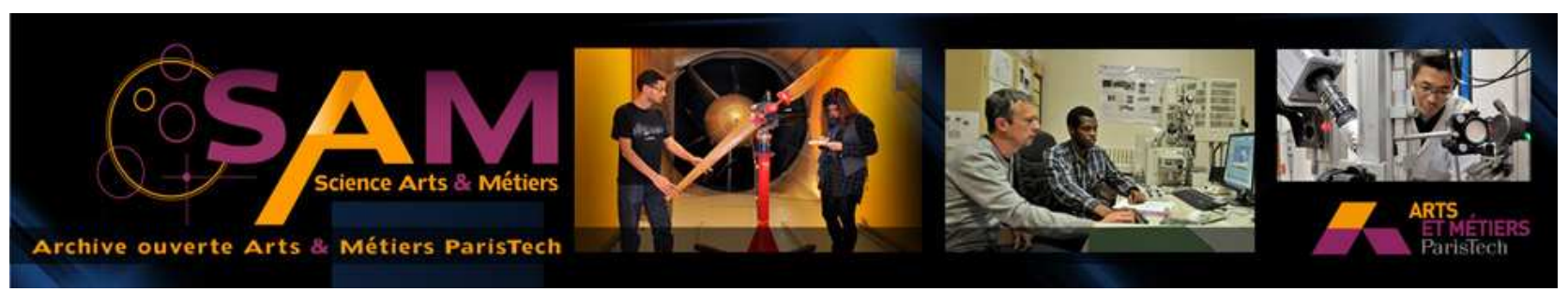

Science Arts \& Métiers (SAM)

is an open access repository that collects the work of Arts et Métiers ParisTech researchers and makes it freely available over the web where possible.

This is an author-deposited version published in: http://sam.ensam.eu

Handle ID: .http://hdl.handle.net/10985/7397

\section{To cite this version :}

Dimitri GERMAIN, Guillaume FROMENTIN, Gérard POULACHON, Stéphanie BISSEY BRETON From large-scale to micro machining: a review of force prediction models - Journal of Manufacturing Processes - Vol. 15, p.389-401-2013 


\title{
From large-scale to micro machining: a review of force prediction models
}

\author{
Dimitri GERMAIN ${ }^{\mathrm{a}, \mathrm{b}}$, Guillaume FROMENTIN ${ }^{\mathrm{b}, *}$, Gérard POULACHON ${ }^{\mathrm{b}}$, \\ Stéphanie BISSEY-BRETON ${ }^{\mathrm{a}}$ \\ ${ }^{a}$ CEA, DAM, Valduc, 21120 Is-sur-Tille, France \\ ${ }^{b}$ Arts et Metiers ParisTech, LaBoMaP, rue Porte de Paris, 71250 Cluny, France
}

\begin{abstract}
In this paper, a review of work performed in the area of force modelling in metal cutting processes is presented. Past and present trends are described and criticised to compare their relevance with current requirements. Several approaches are reviewed, such as empirical, mechanistic and analytical models. The models' ability to predict forces, from rough machining to finish machining, is analysed.

Keywords: Machining, cutting forces, modelling, mechanistic, analytical
\end{abstract}

$\begin{array}{ll}\text { Nomenclature } \\ \beta & \text { Friction angle } \\ \dot{\epsilon} & \text { Strain rate } \\ \dot{\gamma} & \text { Shear strain rate } \\ \epsilon & \text { Strain } \\ \eta_{c} & \text { Chip flow angle } \\ \gamma & \text { Shear strain } \\ \gamma_{n e} & \quad \text { Normal working rake angle }\end{array}$

*Corresponding author. Tel.: +33 3855953 30; fax: +33385595370 .

Email address: guillaume.fromentin@ensam.eu (Guillaume FROMENTIN)

Preprint submitted to Journal of Materials Processing Technology

March 5, 2013 


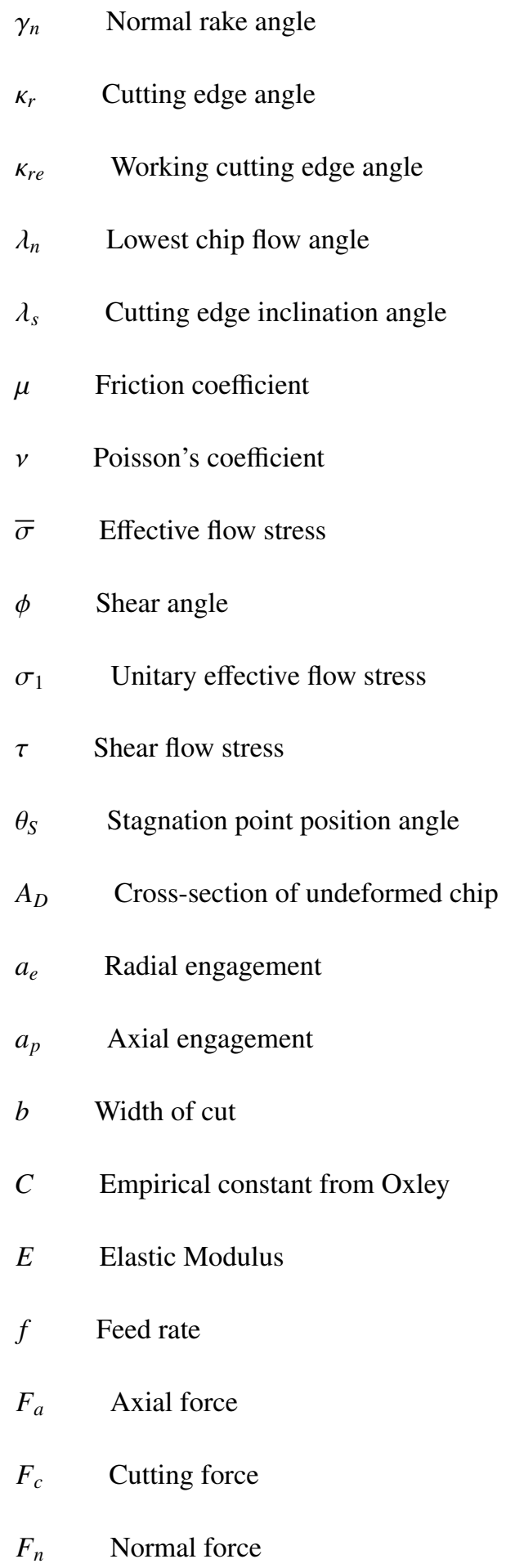




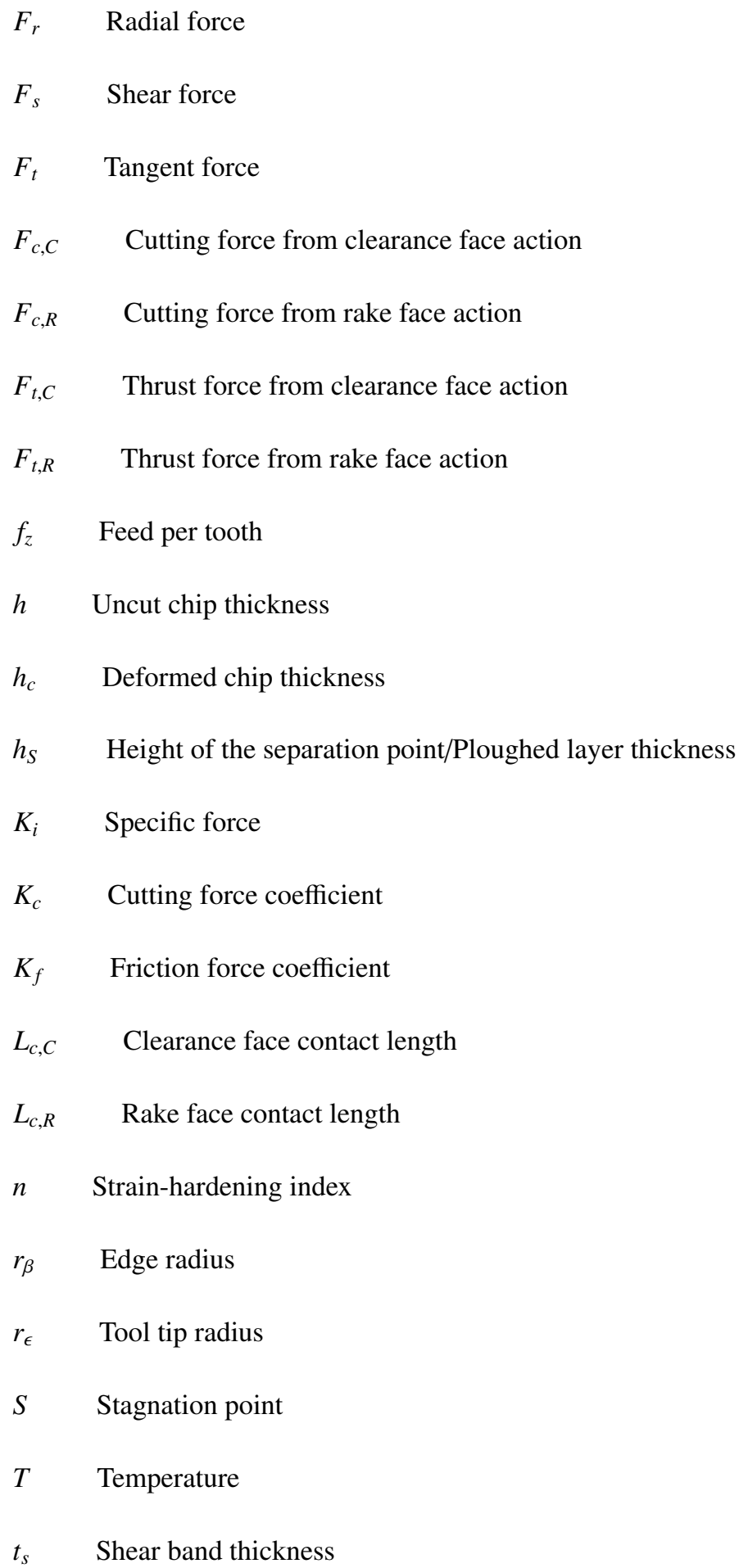


$V_{c} \quad$ Cutting speed

$V_{g} \quad$ Sliding velocity (chip)

$V_{i} \quad$ Clearance face interference volume

$V_{s} \quad$ Shear velocity

\section{Introduction}

The understanding and modelling of cutting processes, initiated by Merchant (1944) during the 1940s, has greatly contributed to maintaining this technology at peak level in spite of issues related to high-performance materials. Today's high-performance machining requires pre-study; predicting surface integrity or workpiece morphology often leads to a gain both in time and money. Moreover, such predictions may improve tool geometries, coatings or machining strategies, which leads to a reduction in the number of qualification tests. A reliable prediction of the cutting forces is a useful parameter in the design of jigs, fixtures, chatter prediction, power requirements, etc. Recent developments in computer-aided process planning confirm this need for machining force prediction.

Several models have been published since Merchant (1944). As shown in figure 1 , most of the analytical models were developed up to the 1970s, before the rise of the mechanistic approach during the 1980s. Since machining is a process involving multiphysics phenomena, each model uses a selection of relevant parameters to focus on a particular application. This paper presents a critical review of the models existing in the literature.

\section{Empirical and mechanistic models}

\subsection{General models}

Empirical models have the specific characteristic of giving very good results. They are often derived from the interpolation of curves and barely have a physical meaning. Their main weakness is their validity in some cases, giving rise to doubts concerning 


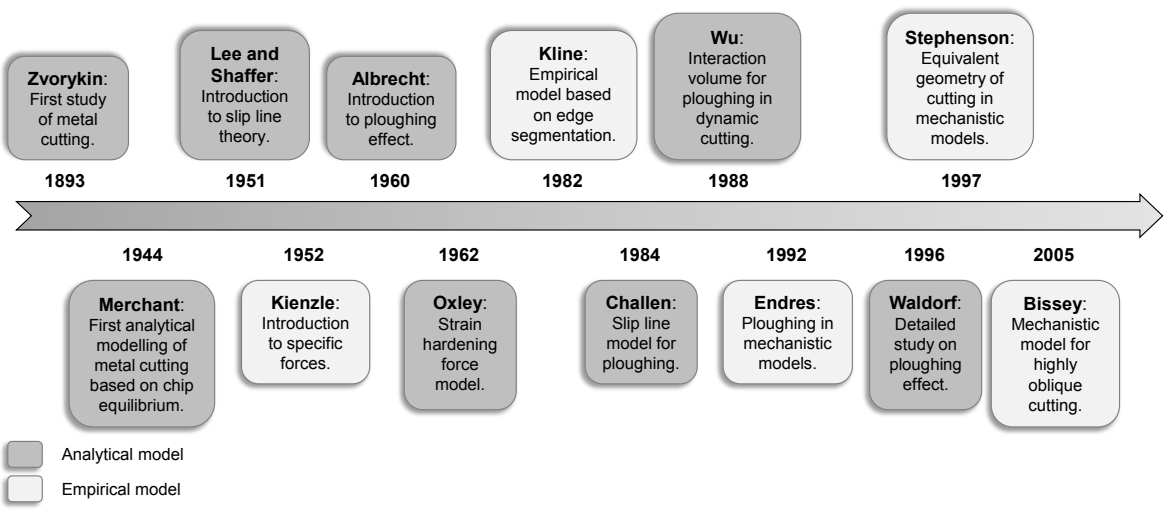

Figure 1: Force modelling history

their effectiveness. Since they are independent of cutting mechanics, empirical and mechanistic models provide forces for the three-dimensional cutting process, skipping the orthogonal modelling step. Mechanistic models are based on the concept of chip load.

Kline et al. (1982) proposed an empirical model for milling based on the principle of edge segmentation. The tool is decomposed into several elementary slices to which basic forces are applied. These vary depending on the tool's angular position. The sum of these contributions for a given angular position provides the overall force at time $t$. The coefficients used by the cutting relationship are obtained from a second-order polynomial function of the axial and radial engagements, respectively $a_{p}$ and $a_{e}$ and the feed per tooth $f_{z}$.

Soon the idea arose of correlating easily observable parameters with the cutting forces. The first traces of this method are in the work of Kienzle and Victor (1952), which introduced the concept of specific forces $K_{i}$ in the three directions (cutting $c$, thrust $t$ and feed $f$ ) according to parameters identified experimentally $\left(K_{11, i}\right.$ and $\left.m_{i}\right)$ (Cf. equation (1)). The force is called specific because it is linked to a cutting width $b$ and a feed unit $f$, i.e. for a tooth in milling and a rotation in turning, hence the index 11. To refine the model, specific force $K_{11, i}$ is often multiplied by a number of correction factors dependent on parameters such as rake angle $\left(K_{\gamma_{n}, i}\right)$, edge inclination angle $\left(K_{\lambda_{s}, i}\right)$, cutting velocity $\left(K_{V_{c}, i}\right)$, etc (Günay et al., 2004; Saglam et al., 2007). This 
concept is still used by the tool-material pair method (AFNOR, 1994). More recently, this approach has been taken up and developed by Denkena et al. (2005) in a force model for milling operations, giving satisfactory results.

$$
K_{i}=K_{11, i}\left(\frac{h}{h_{0}}\right)^{-m_{i}} \quad i \in\{c, t, f\}
$$

Following the work of Kienzle, the idea that force is directly related to the cut sections was developed, especially at the Department of Industrial Engineering at the University of Illinois at Urbana-Champaign (Kapoor et al., 1998). The idea of mechanistic models is that forces are proportional to the chip section $A_{D}$, i.e. the cross-sectional area of the chip in the reference plane. The coefficients are dependent on cutting conditions, tool geometry and material properties. An approach to orthogonal cutting often encountered considers that the two force components applied to the cutting edge are proportional to the undeformed chip area through the coefficients $K_{c}$ and $K_{f}$, representing respectively the specific cutting energy (2) and friction energy (3) (Reddy et al., 2000). In the case of oblique cutting, the normal force is orthogonal to the rake face and the frictional force is oriented in the direction of the chip flow defined by the angle $\eta_{c}$. These two equations do not take into account the effect of ploughing on the clearance face.

$$
\begin{aligned}
& F_{c}=K_{c} A_{D} \\
& F_{f}=K_{f} A_{D}
\end{aligned}
$$

Coefficients $K_{c}$ and $K_{f}$ are usually determined by fitting a power law to a batch of experimental results and relating the forces to the cutting speed, feed rate and tool geometry, as in equations (4) and (5) (Reddy et al., 2001).

$$
\begin{aligned}
& \ln K_{c}=a_{0}+a_{h} \ln h+a_{V_{c}} \ln V_{c}+a_{\gamma_{n e}} \ln \left(1-\sin \gamma_{n e}\right)+a_{h V_{c}} \ln V_{c} \ln h \\
& \ln K_{f}=b_{0}+b_{h} \ln h+b_{V_{c}} \ln V_{c}+b_{\gamma_{n e}} \ln \left(1-\sin \gamma_{n e}\right)+b_{h V_{c}} \ln V_{c} \ln h
\end{aligned}
$$

This formulation may vary slightly from one model to another, especially taking into account the interaction between cutting speed $V_{c}$ and uncut chip thickness $h$. It gives considerable flexibility to the model and, therefore, often gives good results. Coefficient $a_{0}$, and coefficient $a_{h}$ linked to the uncut chip thickness, can be respectively associated with the edge effect and approximately with a mean cutting pressure, the area 
between the tool and the chip not being directly linked to the uncut chip thickness. The other coefficients enable parameter effects to be introduced; this is a phenomenological approach, and these coefficients do not have direct physical meaning. Concerning the other force direction, coefficient $K_{f}$, representing the effect of friction, is absolutely not comparable to a friction coefficient but more to a friction stress. However, this consideration is justified when there is no mechanical action on the clearance face. The only interest in these models is the consideration that the cutting forces are proportional to the undeformed chip area $A_{D}$ and a function of cutting speed $V_{c}$, rake angle $\gamma_{n e}$ and uncut chip thickness $h$. Another problem is that parameters such as work material properties or insert orientation also affect forces and are not considered in this case. The model should include these parameters, implying large calibration test batch. Park et al. (2004) tried to avoid this aspect by using FEM simulations to calibrate their model in the case of various microstructures. The predicted forces had average errors of $10 \%$ to $20 \%$, depending on the force component, with a stochastic distribution. Mechanistic models were also designed for honed cutting tools. The ploughing effect generated by the edge radius provides an additional force to the primary shear force. Ranganath et al. (2007) proposed a model with a constant ratio between shearing and ploughing forces in orthogonal machining. The model is based on the same philosophy as equations (4) and (5), but restrained to functions of the rake angle, cutting velocity and uncut chip thickness. To calibrate its model, the author defined three steps. First of all, cutting tests must be performed at constant ratio $h / r_{\beta}$ with two different tools made from the same material but different edge radii. Next, the force ratios for both cutting and thrust forces have to be computed to evaluate the coefficient linked with chip thickness $h$. Finally, the normalised force coefficients are computed and a least-squares regression is performed to compute the coefficient linked with rake angle. In their force model for 3D ball-end milling, Ko and Cho (2005) identified the ploughing effect occurring at the bottom of the mill. The mill is divided into a series of slices of defined thickness (see also Kline et al., 1982). The force coefficients $K_{n}$ and $K_{f}$ strongly increase when the uncut chip thickness becomes smaller than 0.01 micrometre. They are then computed from a Weibull function. The thickness of the slices also influences the force coefficients, and the Weibull function has to be calibrated for a given segmentation rate. 


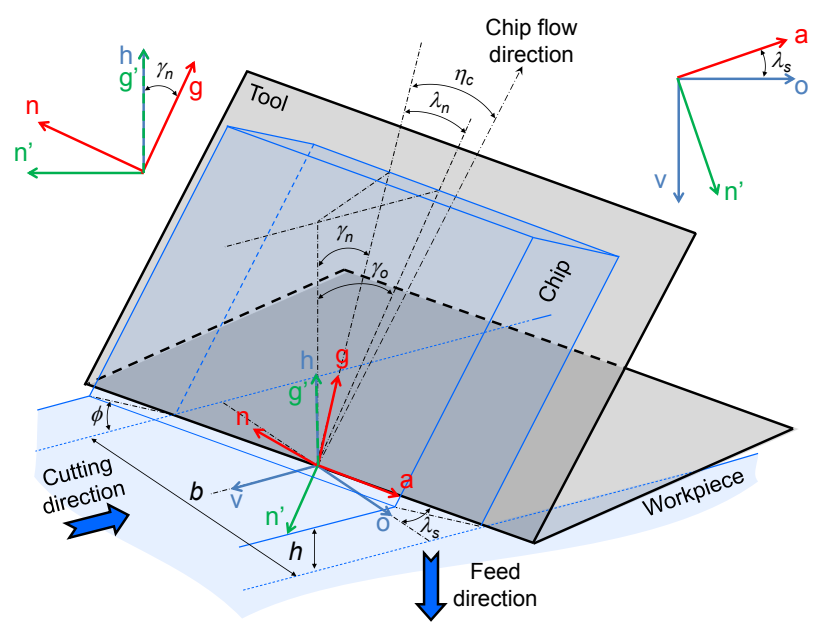

Figure 2: Frame of reference for force modelling, after Bissey et al. (2005)

\subsection{Oblique cutting edge}

The model proposed by Bissey et al. (2005) in oblique cutting is more complex. Designed to be used after segmentation of the tool, this model includes eight factors, some of which are similar to those of the previous models and others reflect the effect of edge angles. The cutting parameters used in the model are uncut chip thickness $h$, width of cut $b$ and the inclination angle of the edge $\lambda_{s}$. The rake angle $\gamma_{n}$ is implicitly used in the formulation of angle $\lambda_{n}$. The chip flow angle $\eta_{c}$ cannot be less than the value of $\lambda_{n}$ and can be computed from the relation given by Armarego and Brown (1969). Figure 2 describes the frame of reference used by the model, in particular the rake face coordinate system $(\vec{g}, \vec{n}, \vec{a})$. The forces are computed from the following relations:

$$
\begin{gathered}
A_{n}=K_{n}\left(\sec \lambda_{s}\right)^{K_{n \lambda_{s}}} \\
F_{n}=-\left(k_{n_{0}}+A_{n} h\right)\left(1+K_{n \gamma}\left(\gamma_{n}-\gamma_{0}\right)\right) b \\
C_{f}=\left(K_{c f_{0}}+K_{c f} h\right)\left(1+K_{c f \lambda_{s}} \lambda_{s}\right)\left(1+K_{c f \gamma}\left(\gamma_{n}-\gamma_{n 0}\right)\right) \\
F_{f r}=\left(A_{n} h C_{f}+F_{f_{0}}\right) b
\end{gathered}
$$

Then, in the directions $\vec{g}$ and $\vec{a}$

$$
\lambda_{n}=\arctan \left(\sin \gamma_{n} \tan \lambda_{s}\right)
$$




$$
\begin{aligned}
& F_{g}=F_{f r} \cos \left(\eta_{c}\right) \\
& F_{a}=F_{f r} \sin \left(\eta_{c}\right)
\end{aligned}
$$

These relations were designed to predict forces with relatively similar tools, i.e. having an edge with the same material, coating and preparation (radius or chamfer). The global geometry of the tool is not initially considered, and the model is applied in a similar way as in Kline et al. (1982). This is the reason why the $\kappa_{r}$ angle does not appear in equations (7) to (12). The calibration of the coefficients is essentially experimental. The forces are predicted within a range of cutting parameters. This range is defined by the standard AFNOR (1994) based on the specific cutting energy. Despite the expression of forces in a frame of reference oriented by the inclination angle $\lambda_{s}$, this angle is used as an input parameter by the model. The weakness of this model is its incapacity to predict forces in the case of low uncut chip thickness, when the ploughing effect occurs. The author revealed some difficulties in calibrating the model near the cutting edge, where the uncut chip thickness is the smallest. In addition, the tool is not characterised by its clearance angle, edge radius or coating properties.

\subsection{Equivalent tool geometry models}

To avoid the problems of force prediction at the boundary of the chip cross-section, Stephenson and Bandyopadhyay (1997) used an equivalent uncut chip area described in figure 3. The authors defined two forces on the rake face of the tool, normal force $N$ and force $P$, parallel to the rake face. These forces define two coefficients, $K_{n}$ and $K_{f}$, which are used to compute the three force components $F_{t}, F_{a}$ and $F_{r}$. Note that $K_{f}$ is a dimensionless parameter representing the friction coefficient on the tool.

$$
\begin{gathered}
K_{n}=C_{n} h_{a v g}^{a_{h}} V_{c}^{a_{V_{c}}}\left(1-\sin \gamma_{e q}\right)^{a_{\gamma_{e q}}} \\
K_{f}=C_{f} h_{\text {avg }}^{b_{h}} V_{c}^{b_{V_{c}}}\left(1-\sin \gamma_{e q}\right)^{b_{\gamma_{e q}}} \\
F_{t}=K_{n} A_{D}\left[\cos \gamma_{n_{s}} \cos \gamma_{e q}+K_{f}\left(\sin \kappa_{r e q} \sin \gamma_{e q}+\cos \kappa_{r e q} \sin \gamma_{n_{s}}\right)\right] \\
F_{a}=K_{n} A_{D}\left[-\cos \gamma_{n_{s}} \sin \gamma_{e q}+K_{f}\left(\sin \kappa_{r e q} \cos \gamma_{e q}\right)\right] \\
F_{r}=K_{n} A_{D}\left[-\sin \gamma_{n_{s}}+K_{f}\left(\cos \kappa_{r e q} \cos \gamma_{n_{s}}\right)\right]
\end{gathered}
$$




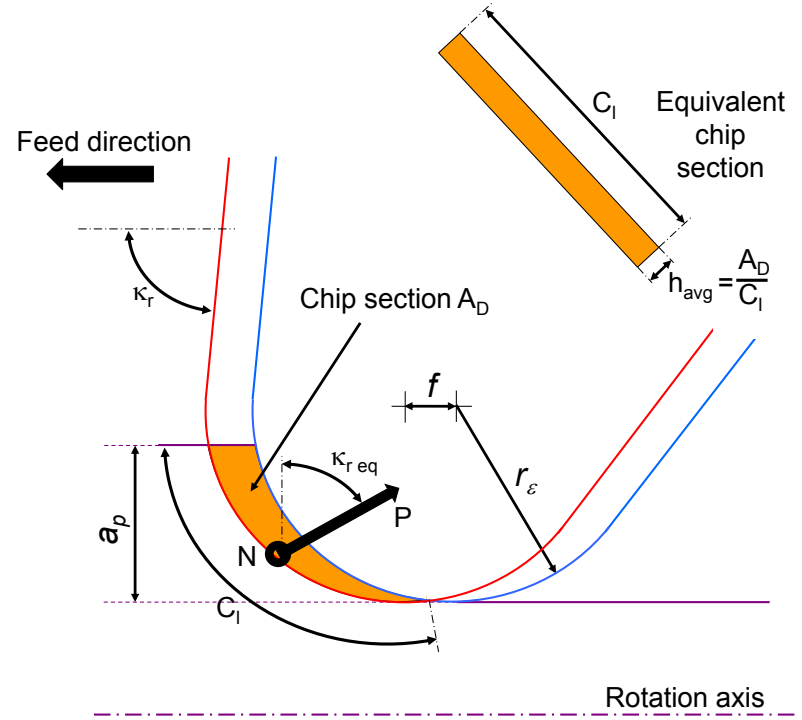

Figure 3: Uncut chip area and its equivalent, after Stephenson and Bandyopadhyay (1997)

Parameters $C$, and exponents $a$ and $b$ are empirical. Only parameter $C_{n}$ is representative of the effect of the work material's hardness and ductility. As for the equivalent chip area, the model considers an equivalent rake angle $\gamma_{e q}$ and an equivalent edge inclination angle $\lambda_{\text {seq }}$. The equivalent edge direction angle $\kappa_{r e q}$ is computed from the form of the cut area. These equivalent parameters are functions of the rake angles $\gamma_{n_{m}}$ and $\gamma_{n_{s}}$ of the main and side cutting edges, and the edge direction angle $\kappa_{r}$.

$$
\lambda_{s e q}=\arctan \left(\tan \gamma_{n_{s}} \sin \kappa_{r}-\tan \gamma_{n_{m}} \cos \kappa_{r}\right)
$$

$$
\gamma_{e q}=\arctan \left(\cos \lambda_{s e q}\left(\tan \gamma_{n_{m}} \sin \kappa_{r}+\tan \gamma_{n_{s}} \cos \kappa_{r}\right)\right) \text { (19) }
$$

Equivalent tool geometry renders the model independent of the process. The model parameters previously determined for a process have the same values in another process when using the equivalent geometrical parameters. Forces can be computed for different processes using geometric transformations. For end turning, bar turning, milling and also drilling, this model has provided accurate results, between $7 \%$ and $16 \%$ mean 
square error, for the tested range of parameters.

In their model, Reddy et al. (2001) defined the equivalent rake and clearance angles for machining with an actuated tool with respect to workpiece geometric variations, e.g. for the machining of a camshaft. In the case of a larger equivalent rake angle, the force decreases and the model using this angle reproduces the experimental observations. Outeiro and Astakhov (2005) and Lee et al. (2008) defined the equivalent rake angle as the tangent to the arc of the edge radius $r_{\beta}$ at the free surface. The forces are obtained by applying the model to each slice. Considering a sliced uncut chip thickness, it is also possible to compute an average equivalent rake angle. This average rake angle depends on the number of elements defined in $h$ and may lead to a loss of information. Vogler et al. (2004) computed the average rake angle from a proportion of the uncut chip thickness $h$.

$$
\begin{gathered}
\gamma_{\text {avg }}=\frac{\pi}{2}-\arctan \frac{\xi h}{u} \\
-r_{\beta} \cos \left[\arcsin \left(\frac{\xi h}{r_{\beta}}-1\right)\right] ; \quad \xi h \leq r_{\beta}\left(1+\sin \gamma_{n}\right) \\
\frac{\xi h-r_{\beta}\left(1+\sin \gamma_{n}\right)}{\tan \left(\frac{\pi}{2}-\gamma_{n}\right)}-r_{\beta} \cos \gamma_{n} ; \quad \xi h>r_{\beta}\left(1+\sin \gamma_{n}\right)
\end{gathered}
$$

with $\xi \geq 1$.

Even if the mechanistic models are basically constants for fitting curves to machining test results, a database of basic cutting quantities can be used in the calibration process. Budak et al. (1996) dimensioned the force coefficients of their model as function of the rake angle $\gamma_{n}$, friction angle $\beta$, edge inclination angle $\lambda_{s}$, chip flow angle $\eta_{c}$ and shear stress $\tau$,

$$
\begin{gathered}
K_{t c}=\frac{\tau}{\sin \phi_{n}} \frac{\cos \left(\beta_{n}-\gamma_{n}\right)+\tan \eta_{c} \sin \beta_{n} \tan \lambda_{s}}{c}, \\
K_{r c}=\frac{\tau}{\sin \phi_{n} \cos \lambda_{s}} \frac{\sin \left(\beta_{n}-\gamma_{n}\right)}{c}, \\
K_{a c}=\frac{\tau}{\sin \phi_{n}} \frac{\cos \left(\beta_{n}-\gamma_{n}\right) \tan \lambda_{s}-\tan \eta_{c} \sin \beta_{n}}{c},
\end{gathered}
$$


with

$$
\begin{gathered}
c=\sqrt{\cos ^{2}\left(\phi_{n}+\beta_{n}-\gamma_{n}\right)+\tan ^{2} \eta_{c} \sin ^{2} \beta_{n}}, \\
\tan \gamma_{n}=\tan \gamma_{o} \cos \lambda_{s}
\end{gathered}
$$

and

$$
\tan \beta_{n}=\tan \beta \cos \eta_{c}
$$

Then, if the tool geometry $\left(\gamma_{n}, \lambda_{s}\right)$, the work material shear stress $(\tau)$ and two of the three parameters $\phi_{n}, \beta$ and $\eta_{c}$ are known, the force coefficients can be determined. These three parameters can be obtained from basic orthogonal and oblique cutting tests. The ploughing forces can be determined from an extrapolation of the force signals to zero uncut chip thickness. With this analysis, the equivalent rake angle due to the edge radius $r_{\beta}$ at small chip thickness is not considered, as mentioned by the authors, which remains a weakness of the model. Concerning the shear stress $\tau$, a data bank of dynamic shear tests on split Hopkinson bars could be an alternative to orthogonal cutting tests. The experiments were carried out on Ti6Al4V alloy. As with all titanium alloys, temperature effects are important. The authors noticed the stability of the shear stress value over the cutting velocity variations and assumed its constantness due to the opposite effect of heat on the strain rate. Another work material might increase the standard deviation of the average shear stress and then introduce a discrepancy between experimental and predicted forces. The friction angle $\beta$ is basically the average value of the friction angles in the sticking and sliding regions. The length of these regions is mainly affected by the rake angle $\gamma_{n}$. The lowest cutting velocities also affect the friction properties but are barely used in common applications and are reserved for special cases. The maximum deviation observed with this model on Ti6Al4V is less than $25 \%$ for $80 \%$ of the test batch. This study is interesting because of its consideration of a database of fundamental quantities such as shear stress and the geometry of the machined zone. However, it is also a good illustration of the limits of the generalisation of mechanistic models.

Empirical and mechanistic models are designed to predict forces without a perfect understanding of the cutting mechanics. As shown in this paragraph, their relatively simple structure and low flexibility make them more adapted to engineering necessity 
than scientific challenge. Work material properties and tool damage, which have a significant effect on forces, are generally not considered in these models. To counteract these weaknesses, analytical models consider the basic quantities of metal cutting to predict forces within a necessary minimum of empirical parameters as statistical results.

\section{Analytical models}

Analytical models are built from relationships derived from mechanics, material science or physics. Their complexity may vary from the machining scale they are destined for, implying various degrees of accuracy. Analytical models are designed to predict forces, but also provide intermediary quantities such as stresses, strains, etc. Assumed to be physically significant, a minimum number of empirical or statistical results are employed to fit the multiphysical process that machining represents.

\subsection{Slip line models}

The pioneering work done by Merchant (1944) presents a model of orthogonal cutting for a homogeneous and isotropic work material with purely rigid plastic behaviour. In this case, the primary shear is assumed to be confined in a plane and the movement of the chip on the rake face of the tool is governed by a friction angle $\beta$. This simplified model does not allow the assessment of the influence of parameters such as cutting speed, edge sharpness or the mechanical properties of the work material. In particular, the friction model used does not reflect perfectly the conditions under which the chip flows. The contact length on the rake face is also not considered as a parameter governing force intensity, as it is neither measured nor calculated. The strength of this model is the circle of forces shown in figure 4 . The calculation of the primary shear angle (35), a key parameter of the model, depends on the cutting angle $\gamma_{n}$ and the angle of friction $\beta$ (Cf. 1). The latter can be determined by equation (28) depending on the cutting angle $\gamma_{n e}$ and the two force components $F_{t}$ and $F_{r}$. The shear stress is a function of these force components, the primary shear angle $\phi$, the uncut chip thickness $h$ and the width of cut $b(29)$. 


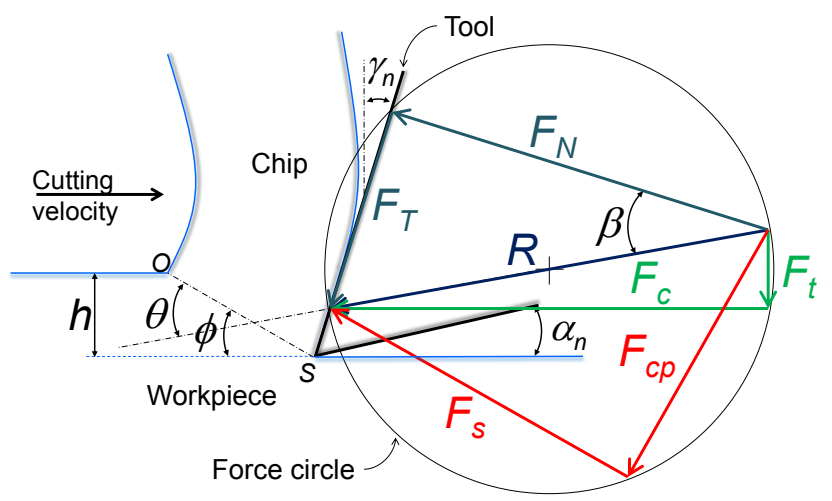

Figure 4: Force analysis in metal cutting without a clearance face effect

$$
\begin{gathered}
\mu=\tan \beta=\frac{F_{t}+F_{c} \tan \gamma_{n e}}{F_{c}-F_{t} \tan \gamma_{n e}} \\
\tau=\frac{\left(F_{c} \cos \phi-F_{t} \sin \phi\right) \sin \phi}{b h}
\end{gathered}
$$

This model is not applicable to all machining applications (for example, superfinish machining), due to its simplifying assumptions. First of all, the edge sharpness is considered as perfect $\left(r_{\beta}=0\right)$. Secondly, the action of the clearance face is totally neglected. Thirdly, the primary shear angle $\phi$ is assumed to be independent of the cutting speed and uncut chip thickness $h$. Finally, the chip is considered to be formed by internal plane sliding and assumes no discontinuities like in saw tooth chips. The Merchant model is therefore intended to model the influence of edge radius free tools for plastic materials with low friction resistance.

Recently, Fang (2003) proposed a new contribution to the slip line model, including certain major aspects, developed over the past few decades, and mentioned below.

\subsection{Shear angle prediction}

The model of Merchant (1944) opened the way to many research programs on force modelling. One of the main difficulties in computing a force model based on slip lines is the accurate prediction of the shear angle. This angle is the essential starting point of every shear plane model. In 1893, Zvorykin (1893) considered the principle of minimal 
energy for chip formation and published the relation (34) to predict the shear angle $\phi$ (Cf. table 1). Note that equations (34) and (35) are almost similar and depend on both rake and mean friction angles. In fact, Merchant (1944) applied the same principle and obtained $A_{1}=\frac{\pi}{4}$ and $A_{2}=\frac{1}{2}$. Later, Lee and Shaffer (1951) published another relation (36) for the shear angle $\phi$ based on the same consideration but in a triangular plastic zone. Their relation has the same form and differs from Merchant (1944) by the parameter $A_{2}$ equal to unity. Several studies carried out by Thomsen et al. (1965); Molinari and Moufki (2008); Moufki et al. (1998) have proved that the relation of Zvorykin (1893) is in better agreement with different coefficients than those published by Merchant (1944) and Lee and Shaffer (1951), even in the case of thick plastic zones (Bitans and Brown, 1965). According to Shaw (2005), a dimensional analysis reveals the shear angle as a function of both normal rake angle $\gamma_{n}$ and friction angle $\beta$. The relation of Stabler (1951) is a function of $\gamma_{n}$ and $\beta$ but differs from Zvorykin (1893)'s form despite being obtained from the same minimal energy considerations. Another formulation proposed by Merchant considers shear stress linearly linked to normal stress as

$$
\tau_{s}=\tau_{0}-K \sigma_{s}
$$

and has provided several values of $K$ for a variety of work and tool materials. This model is the most acceptable according to Shaw (2005) but is unsatisfactory for Zorev (1966). As pointed out by Zorev (1966), these relations do not consider the influence of cutting speed and strain rate. Moreover, these types of model are the most commonly used but do not properly consider the properties of the work material. Oxley (1962) has considered work-hardening in the computation of the shear angle and has shown a good agreement with experimental results. The stress distribution in the shear band is linked to the shear angle that has to be selected to give a resultant force consistent with the friction angle as follows

$$
\begin{gathered}
\sigma_{O}=\tau_{O S}\left(1+2\left(\frac{\pi}{4}-\phi\right)\right) \\
\sigma_{S}=\tau_{O S}\left(\frac{\cos \left(2\left(\phi-\gamma_{n}\right)\right)}{\tan \beta}-\sin \left(2\left(\phi-\gamma_{n}\right)\right)\right) \\
\tan \left(\phi+\beta-\gamma_{n}\right)=\frac{3 \sigma_{O}+\sigma_{S}}{4 \tau_{O D}} .
\end{gathered}
$$


Hydrostatic stresses $\sigma_{O}$ and $\sigma_{S}$ are functions of shear stress $\tau_{O S}$ and the distribution along $O S$ is assumed to be linear, as shown in figure 4. The angle $\theta=\phi+\beta-\gamma_{n}$ between the resultant $R$ of the forces and the shear plane is given by relation (33), whose left member is from geometrical observations. Thus, for given values of $\beta$ and $\gamma_{n}$, equations (31), (32) and (33) are sufficient to determine the angle $\phi$. This solution is in relatively good agreement with the experimental data (Arsecularatne and Mathew, 2000).

\begin{tabular}{|c|c|c|}
\hline Source & Equation & \\
\hline Zvorykin, 1893 & $\phi=A_{1}+A_{2}\left(\gamma_{n}-\beta\right)$ & (34) \\
\hline Merchant, 1944 & $\phi=\frac{\pi}{4}+\frac{1}{2}\left(\gamma_{n}-\beta\right)$ & $(35)$ \\
\hline Lee and Shaffer, 1951 & $\phi=\frac{\pi}{4}+\left(\gamma_{n}-\beta\right)$ & (36) \\
\hline Sata, 1963 & $\cos \phi=\cot \theta+\frac{\cos \theta}{4 \sin \left(\theta+\gamma_{n}\right)} \frac{\tau}{\tau_{f}} \frac{L_{c, R}}{h}$ & (37) \\
\hline
\end{tabular}

Table 1: Equations for shear angle prediction

Different formulae exist to predict the shear angle but there is no universal solution. The chip is generated by a shear process which is affected by the friction conditions on the rake face. This explains the omnipresence of parameters $\gamma_{n}$ and $\beta$ in shear angle models. At low cutting speeds, a built-up edge may appear. This is probably why certain models are not compatible with low cutting speeds. The work materials are mostly sensitive to stain hardening; thus, the solution of Oxley (1962) seems to be the most reliable. Hill (1954) and Dewhurst (1978) have suggested that the solution is not unique and depends on initial conditions.

\subsection{Stresses and strains in chip formation}

The shear band is subjected to significant stresses, strains and strain rates. In most models, the work material flow stress is assumed to be constant during the shearing pro- 
cess for a given work material, rather than varying with cutting conditions and the chip formation area. This assumption has been experimentally observed by Shaw (2005) over a wide range of cutting conditions. Bitans and Brown (1965) explained that the shear zone has a finite thickness, which reinforces the assumption of an equivalent shear plane as displayed in figure 5. Thomsen et al. (1965) depicted the compressive and shear stress state to be constant in the shear plane if its curvature is small enough. In case of a concave or convex curvature respectively, the compressive stress decreases or increases from the free surface to the tool tip. During the shearing process, the work material is strongly deformed $(\epsilon \approx 1)$ at a high strain rate $\left(\dot{\epsilon} \approx 10^{5} \mathrm{~s}^{-1}\right)$ inducing considerable heat production. The greater the heat generated, the lower the shear flow stress is. Strain-hardening produces an increase in the flow stress. The experimental process usually used to reproduce such behaviour, in order to calibrate models, consists of dynamic shear tests on split Hopkinson bars (SHBT). However, to calibrate the models at high temperatures, the sample is usually pre-heated during machining; the heat is only generated by the shearing process. The widely-used model to describe the plastic behaviour of the work material is the strain-hardening model of Norton-Hoff for a given strain-rate and temperature

$$
\bar{\sigma}=\sigma_{1} \bar{\epsilon}^{n},
$$

in which $\bar{\sigma}$ and $\bar{\epsilon}$ are the uniaxial (effective) flow stress and strain of the material, $\sigma_{1}$ is the stress for a deformation $\bar{\epsilon}=1$ and $n$ is the strain-hardening index. When the deformation is greater than 1 , the law changes to linear behaviour, as

$$
\bar{\sigma}=A+B \bar{\epsilon} .
$$

Constants $A$ and $B$ provide the same slope at $\epsilon=1$ and can be expressed as

$$
\begin{aligned}
& A=(1-n) \sigma_{1}, \\
& B=n \sigma_{1} .
\end{aligned}
$$

Assuming the shear flow stress to be uniform along the shear plane, the shear stress in the shear plane is represented by the shear flow stress. This model is the one used by Oxley (1998) in his slip-lines theory, with

$$
\bar{\tau}=\frac{\sigma_{1}}{\sqrt{3}} \bar{\epsilon}^{n} .
$$




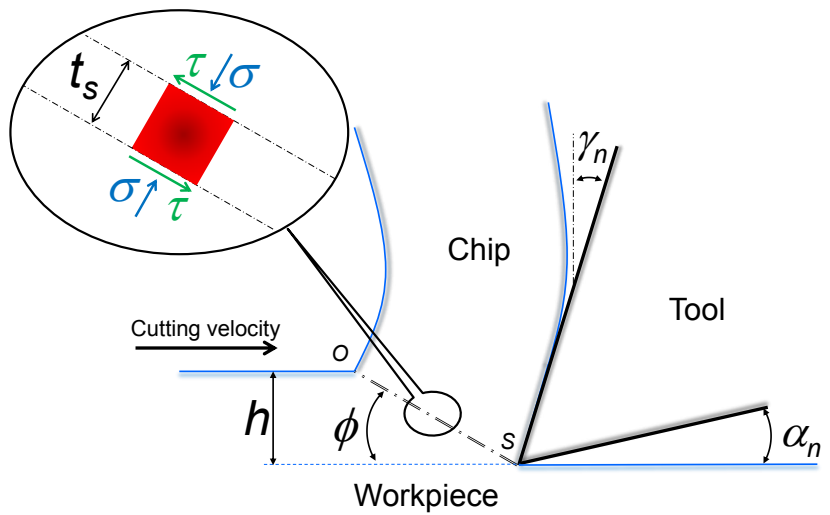

Figure 5: Stress state of the shear band

Some authors, such as Boothroyd and Bailey (1966), used the same type of relation but as a function of strain-rate. The flow stress model used by Dudzinski and Molinari (1997) is a power law function of the shear strain $\bar{\gamma}$, strain-rate $\dot{\gamma}$ and temperature $T$ for an isotropic and rigid material

$$
\bar{\tau}=\mu_{0}\left(\gamma-\gamma_{p}\right)^{n} \dot{\bar{\gamma}}^{m} \bar{T}^{v}
$$

where $\gamma_{p}$ is the pre-strain, $\mu_{0}$ is a material constant, $n$ is the strain-hardening index, $m$ is the strain-rate sensitivity index and $v$ is the thermal softening coefficient. The main drawback of using such a model is the estimation of the mean shear strain-rate $\dot{\bar{\gamma}}=V_{s} / t_{s}$. As the shear velocity $V_{s}$ can be simply computed from cutting and chip flow velocities, the shear band thickness $t_{s}$ remains an unknown parameter. The effective shear strain in the middle of the shear band is usually expressed as

$$
\bar{\gamma}=\frac{\cos \gamma_{n}}{2 \sin \phi \cos \left(\phi-\gamma_{n}\right)} .
$$

Using the Von Mises criterion, the equivalent strain is given by

$$
\bar{\epsilon}=\frac{\bar{\gamma}}{\sqrt{3}} .
$$

The strain-rate can be computed as

$$
\dot{\bar{\epsilon}}=\frac{V_{c} \cos \gamma_{n}}{t_{s} \sqrt{3} \cos \left(\phi-\gamma_{n}\right)},
$$




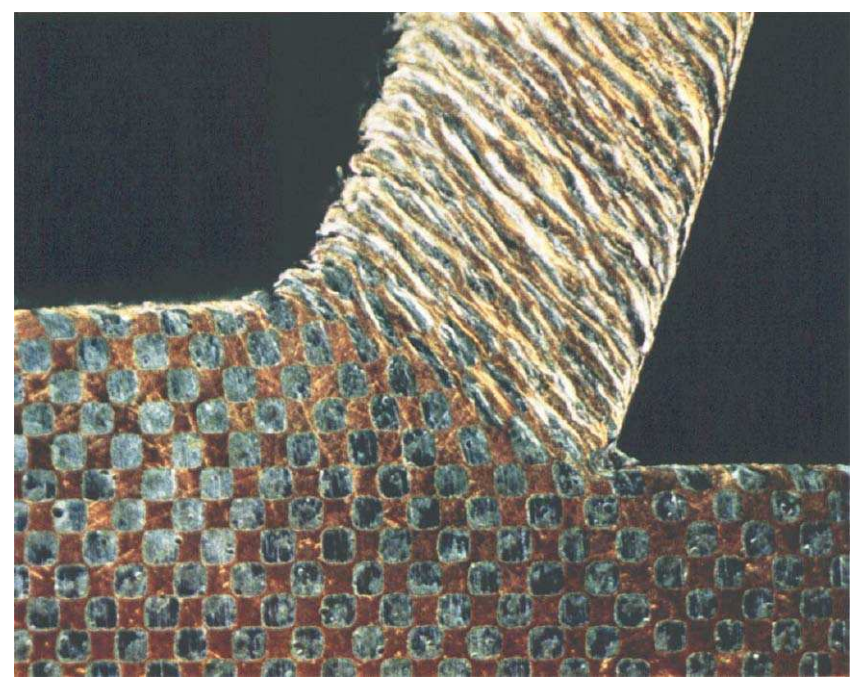

Figure 6: Chip formation zone, after Stevenson and Oxley (1970)

where $t_{s}$ is the shear band thickness. In many analytical models, the shape of the slip lines is necessary to compute the stresses. The type of edge influences their shape, from straight slip lines to multi-curved slip lines. In any case, the slip lines are stressed in shear and compressive loading. Shear loading is due to the action of the tool on the work material due to the cutting velocity, while compressive loading is the consequence of the friction of the chip on the rake face. According to Dewhurst (1978), the stress state solution is not unique and depends on the boundary conditions. Some authors have tried to calibrate the Johnson-Cook constitutive equation from machining experiments (Pujana et al., 2007). This constitutive law is the most commonly used in numerical simulations. The machining theory of Oxley (1998) is based on the previous considerations concerning strain-hardening. An experimental study, based on quickstop tests as shown in figure 6, describes the slip lines as smooth curves parallel to the work material flow velocity. The tool is assumed to be perfectly sharp and the force resultant is computed as

$$
R=\frac{F_{s}}{\cos \theta}=\frac{\bar{\tau} b h}{\sin \phi \cos \theta},
$$

where $\bar{\tau}$ is the shear flow stress in the shear band $O S$ computed from equation (41) and $\theta$ is the angle between the force resultant $R$ and the shear force $F_{s}$. This angle 
is computed applying the stress equilibrium along the shear band for a shear angle $0<\phi<\pi / 4$ as

$$
\tan \theta=1+2\left(\frac{\pi}{4}-\phi\right)-C n,
$$

where $n$ is the strain-hardening index from equation (38) and $C$ is a constant from the empirical strain-rate relation (Oxley and Hastings, 1977)

$$
\dot{\gamma}=\frac{C V_{s} \sin \phi}{h} .
$$

These relations are used to provide an estimation of the hydrostatic stresses at the boundary of the shear band as

$$
P_{O}-P_{S}=2 C n \bar{\tau}
$$

where $P_{O}$ and $P_{S}$ are the hydrostatic stresses at the tool tip and outer bound. In the case of an edge-radiused tool, pressure $P_{S}$ is applied at the stagnation point; the slip line is oriented at $\pi / 4$ (Enahoro and Oxley, 1966). Assuming the slip line to rotate by an angle of $\pi / 4-\phi$ near the free surface, the pressure $P_{O}$ is given by

$$
P_{O}=\bar{\tau}\left(1+2\left(\frac{\pi}{4}-\phi\right)\right)
$$

The normal and coplanar forces to the shear band are then linked by the following relation

$$
F_{n}=F_{s}\left(1+\frac{\pi}{2}-2 \phi-C n\right),
$$

with the shear force $F_{s}$ basically computed as

$$
F_{s}=\frac{\bar{\tau} b h}{\sin \phi}
$$

\subsection{Contact stresses on the rake face}

The loading of the rake face is a direct image of the forces produced in the shear band. In addition, it provides information about the friction properties. In his model, Oxley (1998) considers a uniform normal stress distribution at the tool rake face. As a consequence, the force resultant $R$ intersects the rake face in the middle of the tool/chip contact length $L_{c, R}$. This assumption simplifies the model. Because the work material flows at various speeds on the rake face, the friction coefficient varies along the tool 
chip contact length, especially in the edge hone radius. Generally, the stress distribution on the rake face is chosen with a maximum stress at the tool tip which decreases following a power law as follows,

$$
\begin{gathered}
\sigma_{n}(x)=\sigma_{\max }\left(1-\frac{x}{L_{c, R}}\right)^{n} \\
\tau_{f}(x)=\left\{\begin{array}{ll}
\tau_{p} & \text { if } \mu \sigma_{n} \geq \tau_{p} \text { and } 0<x \leq L_{c, R^{*}} \\
\mu \sigma_{n}(x) & \text { if } \mu \sigma_{n}<\tau_{p} \text { and } L_{c, R^{*}}<x \leq L_{c, R}
\end{array},\right.
\end{gathered}
$$

giving the pattern shown in figure 7. This distribution has been experimentally ob-

\begin{tabular}{cc}
\hline Source & Equation \\
\hline Lee and Shaffer, 1951 & $L_{c, R^{*}}=h \frac{\sqrt{2}}{2 \sin \phi \sin \left(\frac{\pi}{4}+\phi-\gamma_{n}\right)}$ \\
Abdulaze, 1962 & $L_{c, R}=2 h\left(\beta\left(1-\tan \gamma_{n}\right)+\sec \gamma_{n}\right)$ \\
Poletika, 1969 & $L_{c, R}=h\left(\zeta_{1} \beta-\zeta_{2}\right)$ \\
Kato et al., 1972, Toropov and Ko, 2003 & $L_{c, R}=2 h_{c}$ \\
Zhang et al., 1991 & $L_{c, R}=\zeta_{1} h^{\zeta_{2}} V_{c}^{\zeta_{3}}\left(\frac{\pi}{2}-\gamma_{n}\right)^{\zeta_{4}}$ \\
Stephenson et al., 1997 & $L_{c, R}=\zeta_{1}+\zeta_{2} V_{c}$ \\
Toropov and Ko, 2003 & $L_{c, R} *=h_{c}\left(1-\tan \gamma_{n}\right)+\frac{h}{\cos \gamma_{n}}$ \\
Marinov, 1999, Sutter and Molinari, 2005, Woon et al., 2008 \\
Germain et al., 2010 \\
$L_{c, R}=\zeta_{1} h_{c}-\zeta_{2} h$
\end{tabular}

Table 2: Equations for tool-chip contact length prediction

served by Barrow et al. (1982). In their observations, the authors noticed a plateau where the stress remains at its maximum at the tool tip, suggesting a high degree of friction. Another observation, based on temperature measurements and numerical simulation, revealed the same type of stress pattern (Artozoul et al., 2010). Cahuc et al. (2001) consider a stress distribution with a plateau of maximum stress. These stresses are obtained from the stress state of the shear band as

$$
\sigma_{n}(x)=\left\{\begin{array}{ll}
P_{S} & \text { if } 0 \leq x \leq k L_{c, R} \\
\frac{P_{S}}{1-\bar{\tau}} \frac{L_{c, R}-y^{\prime}}{L_{c, R}} & \text { if } k L_{c, R}<x \leq L_{c, R}
\end{array} .\right.
$$




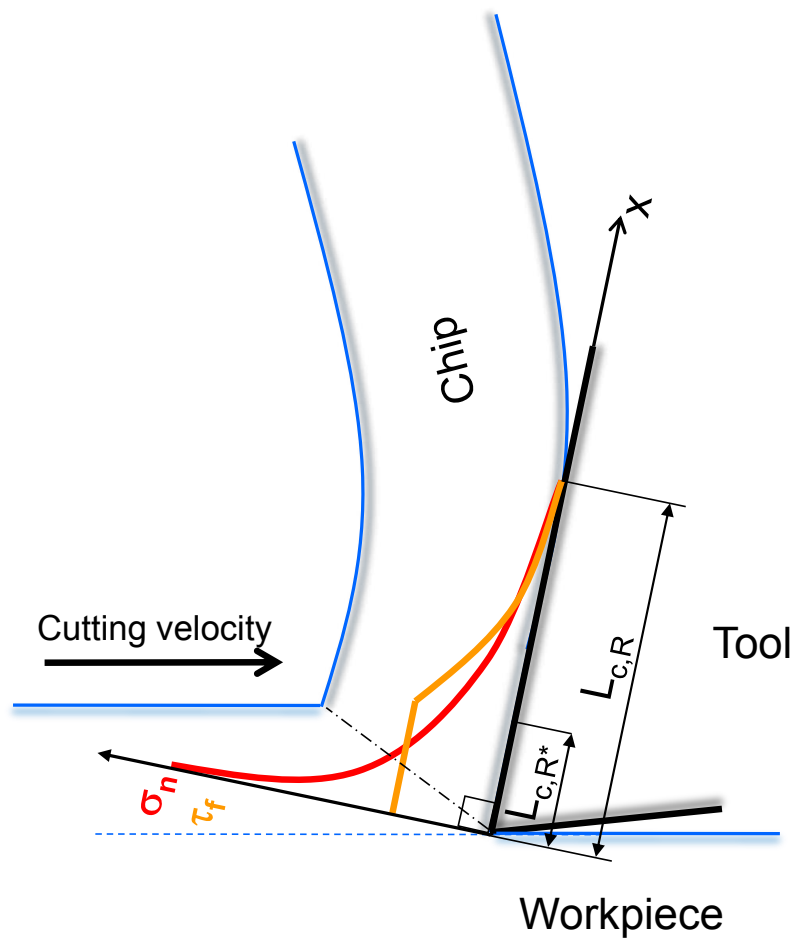

Figure 7: Classic stress distribution on the rake face 
The friction stress distribution is given by

$$
\tau_{f}(x)=\left\{\begin{array}{ll}
\tau_{p} & \text { if } 0 \leq x \leq k L_{c, R} \\
\frac{\tau_{p}}{1-\bar{\tau}} \frac{L_{c, R}-y^{\prime}}{L_{c, R}} & \text { if } k L_{c, R}<x \leq L_{c, R}
\end{array} .\right.
$$

All of the stress distributions are associated with a tool-chip contact length $L_{c, R}$. Oxley (1998) computed the moment equilibrium at the tool tip and obtained the following expression of the rake contact length

$$
L_{c, R}=\frac{h \sin \theta}{\cos \beta \sin \phi}\left(1+\frac{C n}{3\left(1+2\left(\frac{\pi}{4}-\phi\right)-C n\right)}\right) .
$$

The lengths noted with the symbol "*" correspond to the length of the sticking region and not the complete tool-chip contact length. Some friction models provide a non-constant work material velocity $V_{g}$ along the rake face. Bonnet et al. (2008) conducted numerical simulations of stainless steel machining. The speed is equal to zero at the separation point and remains null as long as the work material is in contact with the edge radius. Then $V_{g}$ increases until the end of the length $L_{c, R}$, to arrive at the outlet chip flow velocity $\left(V_{g}\left(L_{c, R}\right)=h / h_{c} V_{c}\right)$, and reaches the cutting speed $V_{c}$ at the end of the clearance contact length $L_{c, C}$. Various approaches to modelling tool chip contact are given in table 2. The parameters taken into account are linked to the studied parameter, and no studies neglect to consider the effect of the rake angle. The different formulations are also explained. All the present models concern machining on common steels with flat rake face tools. The contribution of Poletika (1969) also covered copper and bronze, while Kato et al. (1972) dealt with the cutting of aluminum, copper and zinc, which may explain a formulation including only chip thickness.

In many machining cases, and especially in steel turning, the tool geometry is composed of a chip breaker, reinforced champfer, and/or rounded edge. For decades these aspects have been included in research works, and have been developed more and more since: Jawahir and Oxley (1988), Mesquita and Barata Marques (1992), Fang (2003).

\subsection{Ploughing}

Micromachining or superfinish machining have to deal with important scale effects. When the uncut chip thickness is usually the same or even lower than the edge radius $r_{\beta}$, 
the effective rake angle is affected and becomes strongly negative. This is a geometrical size effect. The flow of work material will be divided, as the main part of the work material will form the chip while a small amount will be ploughed by the clearance face. This is known as the ploughing effect. Furthermore, the stress flow of the work material increases when a low thickness is deformed; this is a material size effect. Often neglected for conventional machining operations, the ploughing phenomenon is the principal cause of surface integrity defects. In dynamic cutting, ploughing is the result of the oscillations of the tool, which produce a periodic contact between the clearance face of the tool and the machined surface. Shaw (1995) also reported that ploughing is the cause of an increasing specific cutting energy at low depth of cut, and Albrecht (1960) considered its effect as the second energy dissipation source after shearing. The separation of the work material can occur at a stagnation point on the tool wedge but also at the apex of a stable built-up edge. The work of Waldorf et al. (1999) deals with the two approaches. In the case of a stagnation point, no built-up edge is created. The root of the shear plane on the cutting edge defines the location of the stagnation point (see Jaspers and Dautzenberg, 2002, pg. 126). The work material above and below this point flows directly over the edge hone to the rake and clearance faces, respectively. The portion of work material below the stagnation point is usually used to define the ploughed depth. L'Vov (1969) and later Waldorf et al. (1999) simply defined this depth as the distance in the feed direction between the stagnation point $S$, visible in figure 8 , and the bottom of the edge (theoretically generating the machined surface without work material recovery)

$$
h_{S}=r_{\beta}\left(1-\cos \theta_{S}\right)
$$

where $\theta_{S}$ is the angular position of $S$. This angle $\theta_{S}$ remains an unknown parameter in this case and needs to be observed. Several formulations have been designed in the case of micromachining. Ikawa et al. (1991) defined, from a molecular dynamics analysis of the nano-machining of pure copper with a diamond tool, that $\cos \theta_{S} \approx 0.9$. The same assumption is employed by Knüfermann (2003) for the hard turning of optical components, while the numerical simulations of Lai et al. (2008) on pure copper with a tungsten carbide tool provide a value of $\cos \theta_{S}=0.75$ when the rake angle is $10 \mathrm{de}$ - 


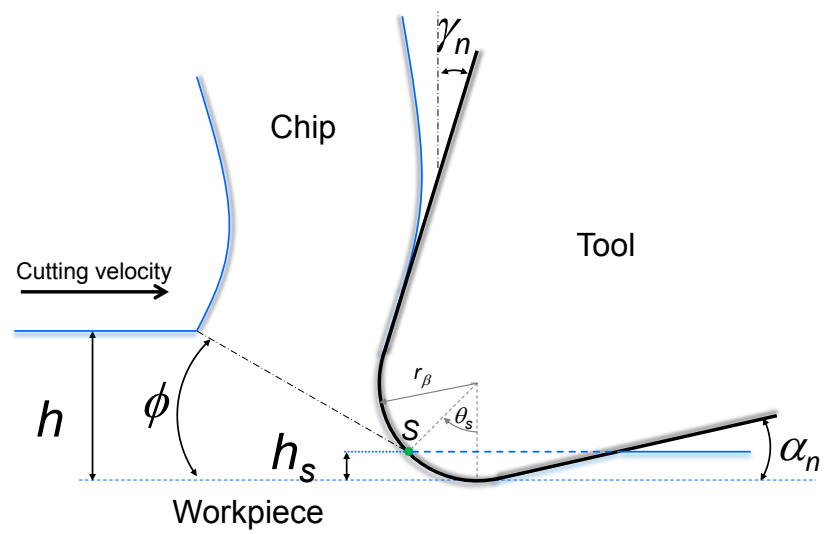

Figure 8: Stagnation point

grees. Kragelskii (1965) underlined the dependence of the stagnation point position on the friction coefficient using the relation $\theta_{S}=-\arcsin \left(1.69\left(\beta^{2}-0.863 \beta-0.405\right)\right)$, and Son et al. (2005) as $\theta_{S}=\pi / 4-\beta / 2$. Considering the ploughed layer as being independent of the shearing process is not fully agreed upon. In their model, Liu et al. (2006) define $h_{S}$ as a function of the stress state and edge hone radius as

$$
h_{s}=r_{\beta}\left(\frac{1}{2}-\frac{\tau_{a}}{\sigma}\right) \text {, }
$$

where $\sigma$ is the flow stress as described in equation (38) and $\tau_{a}$ the shear strength of the adhesive junction. This material parameter is a function of the temperature given by the Clausius-Clapeyron equation as

$$
\tau_{a}=\frac{0.427}{3} L_{m} \rho \ln \frac{T_{m}}{T}
$$

where $L_{m}$ is the latent heat of melting, $\rho$ the material density, $T_{m}$ the melting temperature and $T$ the temperature at the tool/chip interface. The main difficulty resides in the definition of the tool/chip interface temperature, which is not uniform. This study has shown the direct influence of the edge hone radius but also the cutting speed, which influences the stress state for steel but not for aluminium alloys. Endres et al. (1995) defined its depth from an empirical power law based on experimental measurements, separating the ploughing force component from the total forces. The same approach is 


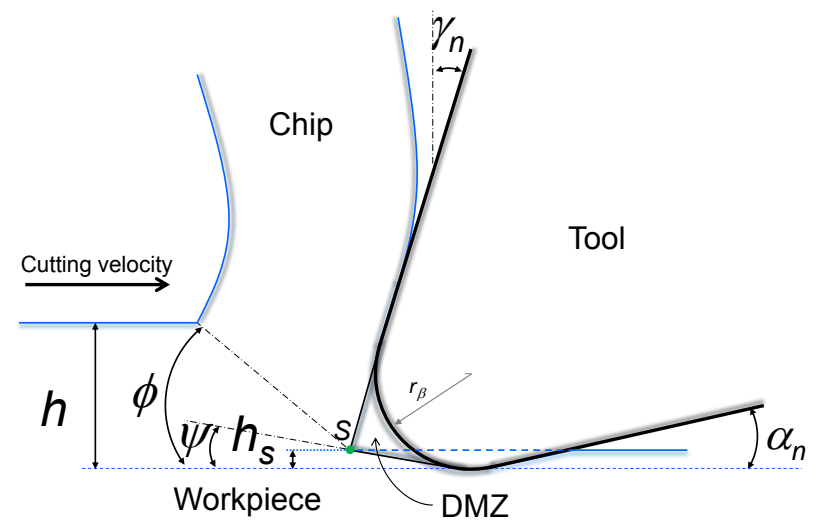

Figure 9: Dead metal zone after Waldorf et al. (1999)

proposed by Yuan et al. (1996) in the case of $h=h_{S}$ with an analytical expression of cutting forces given as an expression of $\theta_{S}$ as follows.

$$
\theta_{S}=\arctan \frac{F_{c}-\mu F_{t}}{\mu F_{c}+F_{t}}
$$

The definition of the ploughed layer $\delta$ given by Manjunathaiah and Endres (2000) is a function of the height of the separation point $h_{S}$ (as defined by Waldorf et al. (1999)), the shear angle $\phi$ and the angle between the lower boundary of the deformed zone and the cutting direction $\psi$, shown in figure 9 .

$$
\delta=\frac{\left(h-h_{S}\right) \cot \phi+r_{\beta} \sin \theta-h}{1+\cot \psi}
$$

In the case of a stable built-up edge or dead metal zone (DMZ), the geometry of the edge is modified into a sharper wedge. The work material is divided at the apex of the DMZ as with a sharp tool. According to Karpat and Özel (2008), the DMZ is encountered with negative rake angles, while stagnation points are reserved for positive cutting geometries. The shape of the DMZ is not as obvious as the theoretical shape of the sharp tool, i.e. a straight extension of both rake and clearance faces. In their model, Waldorf et al. (1999) consider the upper bound of the DMZ as the extension of the rake face, while the lower bound is inclined towards the cutting velocity. This inclination angle $\psi$, given in equation (72), is a function of the rake angle $\gamma_{n}$ and ploughed depth 
$h_{S}$ assumed as the length in the feed direction between the apex of the DMZ and the point generating the machined surface.

$$
\psi=\arctan \left(\frac{h_{S}}{r_{\beta} \tan \left(\frac{\pi}{4}+\frac{\gamma_{n}}{2}\right)-h_{S} \tan \gamma_{n}}\right)
$$

The modelled behaviour of the ploughed layer varies from one author to another. Connolly and Rubenstein (1968), Rubenstein (1990) and Endres et al. (1995) assumed full recovery and Abdelmoneim and Scrutton (1973) considered partial recovery. According to Albrecht (1960) and Abdelmoneim and Scrutton (1974), the ploughed layer does not recover. In fact, Abdelmoneim and Scrutton (1974) assumed a slip line field that does not satisfy the principle of volume constancy. Considering the plastic deformation of the work material at the tool tip and volume constancy, the height of the recovery must be complete. In addition, to satisfy velocity continuity in that region, the work material must recover from the bulk.

An estimation of the ploughing force was given by Albrecht (1960), who extrapolated the force signal to zero uncut chip thickness. The author assumed the extrapolated force to represent the ploughing force. This method assumes a constant ploughing component for a large uncut chip thickness and a shear force component independent of $h$. As the first assumption is quite relevant, the second suggests that the shear flow stress is constant. As explained before, this stress is a function of several parameters, such as strain, which is dependent on the rake angle $\gamma_{n}$. When the uncut chip thickness is of the same order as the edge hone radius, the equivalent rake angle has to be considered. As a consequence, the flow stress is modified and the shear force component becomes indirectly dependent on $h$. The ploughing force is often estimated using this extrapolation method or modelled using the approach proposed by Connolly and Rubenstein (1968). The forces resulting from the ploughing effect are functions of the hydrostatic pressure $P_{p}$ at the tool/workpiece contact, the projected contact surface in the generated surface plane and the friction coefficient $\mu$ in the case of complete work material recovery.

$$
\begin{aligned}
& F_{c, C}=P_{p} r_{\beta}\left(\cos \left(\frac{\pi}{2}-\theta_{S}\right)+\frac{1-\sin \left(\frac{\pi}{2}-\theta_{S}\right)}{\cos \alpha_{n}}\right) b \\
& F_{t, C}=\mu P_{p} r_{\beta}\left(\cos \left(\frac{\pi}{2}-\theta_{S}\right)+\frac{1-\sin \left(\frac{\pi}{2}-\theta_{S}\right)}{\cos \alpha_{n}}\right) b
\end{aligned}
$$


No procedure is given to estimate the pressure $P_{p}$ and the friction coefficient $\mu$. The pressure $P_{p}$ must be the average pressure but the experimental results do not satisfy the theoretical behaviour suggested by indentation and scratch mechanics. The ploughing phenomenon models are sometimes based on these mechanics. Challen and Oxley (1984) proposed a slip line model for scratching and extended it to chip formation with a non-hardening material. A circular particle, which may represent a blunt tool, is rubbing on the work material. This process generates a wedge-shaped asperity from which a chip may be extruded. The contact between the asperity and the particle is assumed to be a chord for the simple asperity and a double chord in the case of chip production. The double chord model is the most suitable for the cutting process, and more specifically for micro machining, and considers a stagnation point. Hertz's theory of elastic contact has been proposed by some authors but remains hard to justify because of the high plasticity resulting from ploughing. The theory of Wu (1988) considers the thrust force on the clearance face $F_{t, C}$ as a function of the normal volumic contact force $K_{p}$ and the interaction volume $V_{i}$; the cutting force component $F_{c, C}$ results from the product of $F_{t, C}$ with the friction coefficient $\mu$. This volume is computed from geometrical relations assuming a complete work recovery and the ploughed depth $h_{S}$. The indentation mechanics of equation (74) gives an estimation of the volume displaced by a rigid cylindrical frictionless indenter under a static load $F_{i}$ as a function of the elasto-plastically affected depth $h_{S}$ and the material elastic constants, which are the elastic modulus $E$ and the Poisson's coefficient $v$. The ratio of $F_{i}$ to $V_{i}$ is equal to the volumic contact force $K_{p}$. Due to the shape of the tool wedge and the cutting speed, static indentation with a cylinder cannot provide results comparable with machining experimentation.

$$
V_{i}=1.29 F_{i} \frac{1-2 v}{E} h_{S}
$$

The use of equations governing elasticity for a plastic phenomenon is also disconcerting. Waldorf et al. (1999) dealt with this approximation problem and considered that, for slightly hardening materials and using relations designed for cylindrical indentation at plastic yielding, the load might be linked to the indentation depth. This depth might be considered as the ploughed depth. Recently, some authors have considered 
the stresses on the clearance face to be continuous with the stresses on the rake face. Cahuc et al. (2001) considered an elastic contact. The stresses at point $S$ are given by equations (64) and (65). An equivalent contact geometry is considered as two linear segments. The first segment $\left(L_{c, C 1}\right)$ corresponds to the portion of the edge hone and the second $\left(L_{c, C 2}\right)$ corresponds to the clearance face. Stress distribution is linear along $L_{c, C}=L_{c, C 1}+L_{c, C 2}$ and decreases to reach zero at the end of the contact.

$$
L_{c, C 2}=\frac{P_{S}\left(1+V_{f}\right)\left(1-r_{\beta}\right)}{E\left(1+V_{c}\right)} C_{A}
$$

Length $L_{c, C 1}$ is calculated using geometrical relations and constant $C_{A}$ is obtained using the method of Albrecht (1960) to determine the force on the clearance face. Woon et al. (2008) performed machining tests and numerical simulations to evaluate the position of the stagnation point. Its position is set at $\theta_{s}=58.5 \pm 0.5$ degrees for $2<h<20$ micrometres. Stress distribution is computed on both rake and clearance faces; friction stress is null at the stagnation point $\left(V_{g}(S)=0\right)$ as described by figure 10. For each face, three zones are identified. The first zone corresponds to the contact length of the shear band centered on $S$. It is a sticking region because of the high pressures induced by the shearing process. The second zone is situated between the end of the first zone and the flat surfaces (rake and clearance), i.e. the edge hone surface without the length in contact with the shear band. In this area, the stresses are assumed to be $80-90 \%$ of the maximum stress. The third zone is situated on the rake and clearance faces and ends when the chip and machined surface are no longer in contact with the tool. For DMZ cases, blunt indentation mechanics can be used. The models are based on slip line fields, primary developed by Hill (1954), which are obtained with flat (Shaw, 1982) and wedge indenters (Grunzweig et al., 1954). The assumption of a frictionless contact is generally made in order to simplify the slip line orientation. In this case, the slip lines obtained with a flat indenter reach it with an angle of $\pi / 4$ and rotate by an angle equal to $\pi / 2$. The pressure acting on the indenter for rigid plastic materials is then equal to

$$
\sigma=\tau(2+\pi)
$$

Waldorf et al. (1999) specifies that multiplying $\tau$ by 5.5 is suitable for an elastic-plastic contact. The angle $\psi$ computed from equation (72) is relatively small to ensure the 


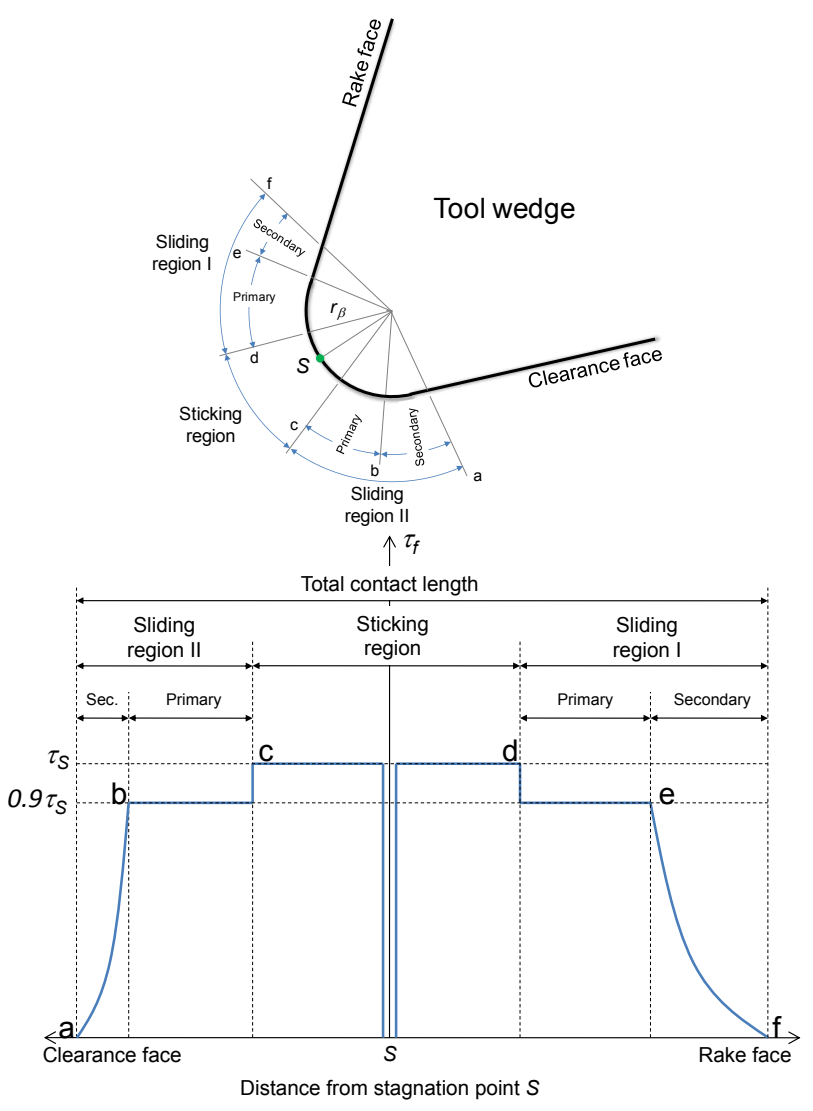

Figure 10: Friction stress distribution on the tool, after Woon et al. (2008) 
assumption of a flat indenter. Equation (76) is designed for a frictionless contact; a friction force component is added as $\tau=\mu \sigma$. This model is suitable when the work material does not recover. The contact pressure expressed in equation (76) refers to a uniform distribution. Because of the configurations of the slip line that forms the shear band and the free surface, i.e. the generated surface, the problem has no symmetry. As a consequence, equation (76) is an idealized model for ploughing force computation.

Fang (2003) proposed a global 27 slip lines model including 12 sub-regions characteristic of the cutting process describing precisely the 3 usual cutting zones. The model concerns a rounded-edge tool and most effects observed in metal cutting are included, among them the ploughing force.

\section{Discussion}

This section will compare the results provided by the models presented above. This comparison is performed for the machining of $\mathrm{CuC} 2$ pure copper, which is a ductile workmaterial, while most models were established for steel. The reference parameters (forces, edge radius, shear angle, tool chip contact length, etc.) are measured from orthogonal machining. Forces are obtained using a piezoelectric dynamometer. Shear angle $\phi$ and contact lengths $L_{c, R}$ and $L_{c, C}$ are measured on images acquired from a video recording of the machining operation.

The conditions for these orthogonal cutting experiments are as follows: the use of MQL, cutting speed and feed equal to $140 \mathrm{~m} / \mathrm{min}$ and $0.075 \mathrm{~mm} / \mathrm{rev}$., uncoated carbide tools with $\gamma_{n} \in\left\{5^{\circ}, 10^{\circ}, 20^{\circ}, 30^{\circ}\right\}$ and $\alpha_{n}$ fixed to $20^{\circ}$.

The accuracy of the analytical models is an important function of the hypothesis required to simplify the multiphysical process of machining. The shear angle is the key parameter of any analytical model. Figure 11 presents the shear angles predicted by the models listed in table 1 . The model of Merchant (1944) clearly overestimates the value of the shear angle $\phi$. The hypothesis of a purely plastic material without strainhardening may explain these results. The global friction coefficient is a mix of the sticking and sliding friction coefficients. Significant sticking could be another explanation for this discrepancy. As Molinari and Moufki (2008) mentioned, the minimum 


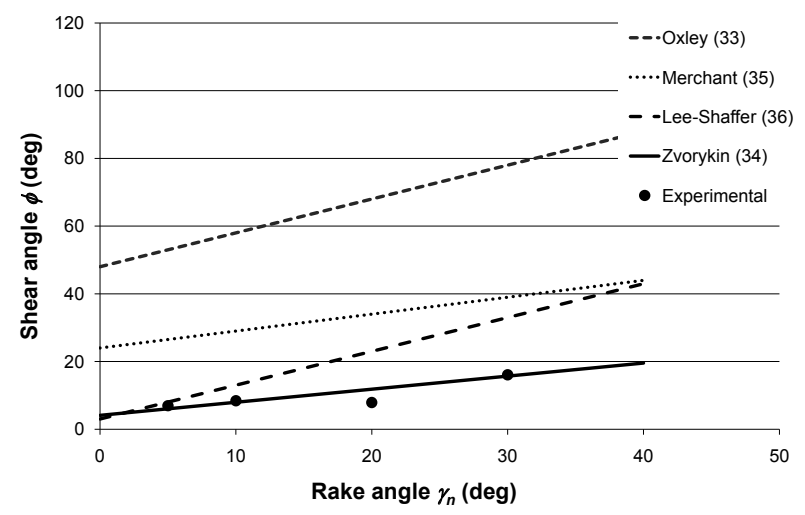

Figure 11: Comparison of shear angle models (see table 1)

energy criterion is not enough to predict this angle. This observation also confirms the results obtained with Lee and Shaffer (1951)'s model. The model of Zvorykin (1893) provides accurate results because of its flexibility. Nevertheless, the calibration of its constants requires a batch of measured shear angles. There is no purely physical model for shear angle prediction.

The tool-chip contact length is not a key parameter like the shear angle can be. It becomes useful when the stress distribution on the rake face is required, e.g. for restricted contact length tool design, etc. Figure 12 presents the response of the models listed in table 2 to rake angle variation. The empirical models provide the best results because of their two degrees of freedom. Germain et al. (2010) assume the contact length to be dependent on the chip thickness because of its bending ability, but they also note the effect of the rake angle. Unfortunately, the relation is only suitable for $\gamma_{n} \leq 30$ degrees. The model of Toropov and Ko (2003) clearly overestimates the contact length because it only considers chip thickness $h_{c}$. The analytical models are assumed to predict only the sticking contact length. The results obtained from Lee and Shaffer (1951) already overestimate $L_{c, R}$ for the highest rake angles. Thus, this model is not suitable, at least for copper machining. The results obtained from equation (61) are quite interesting. The predicted sticking length remains below the total measured contact lengths. The shift between the curve and the experimental values suggests that 


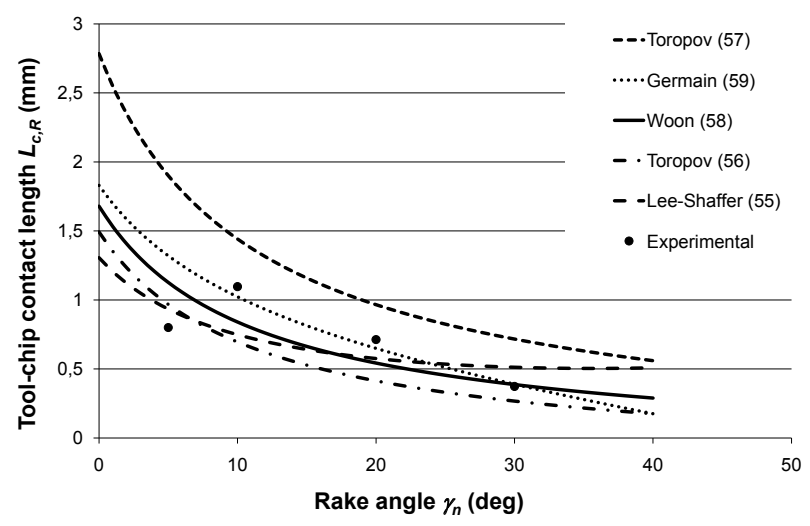

Figure 12: Comparison of tool-chip contact length models (see table 2)

the contact on the rake face becomes a purely sticking contact for high values of $\gamma_{n}$. Sticking usually occurs with very high contact pressure. The highest contact pressures are obtained with the lowest rake angles and at the vicinity of the stagnation point, i.e. the edge hone.

As expected, the mechanistic models are the most accurate ones. Because of its large number of degrees of freedom, the model of Bissey et al. (2005) has the lowest residuals (near to zero). The model of Budak et al. (1996) makes the transition between mechanistic and analytic modelling. The results provided by this model are quite close to the experimental ones. The resultant force is seen, in figure 13, to strongly decrease when the rake angle becomes large, but only slightly for the lowest values. The same behaviour is depicted by the model of Oxley (1998). The resultant force slightly decreases when the smallest rake angle decreases. The slope increases significantly when the rake angle becomes large. The model of Cahuc et al. (2001) has the exact opposite behaviour.

The ploughed layer depth is described by most models as independent of the rake angle. Only the models of Yuan et al. (1996) and Liu et al. (2006), in figure 14, show any consistency regarding rake angle variation. While the results obtained from Yuan et al. (1996) are the opposite of the experimental results, the results of Liu et al. (2006) show the same trend, but the estimated temperature used in equation (69) may explain 


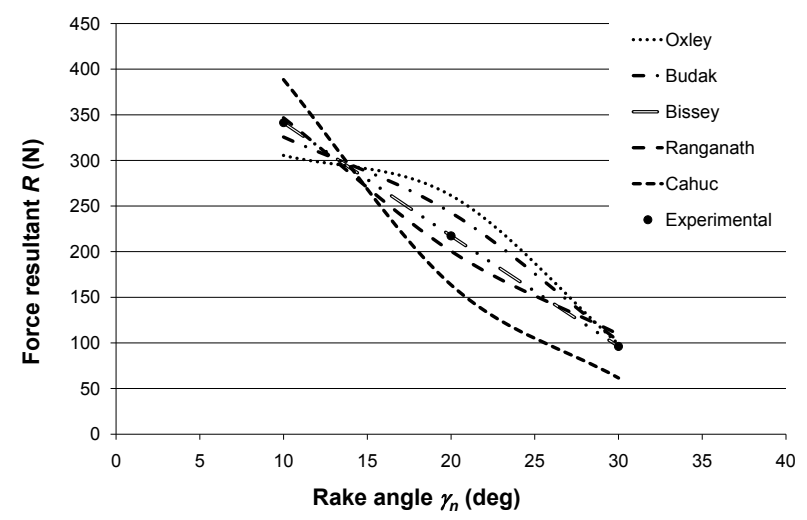

Figure 13: Comparison of the predicted force resultants

its lack of accuracy.

\section{Conclusions}

Force modelling remains the aim of many researchers and is currently experiencing a certain revival. This paper has presented various approaches.

The mechanistic approach is present in the most recent studies. Its simplicity and fast capacity to predict accurate forces is the reason for its popularity. However, these models may not be valid for a wide range of cutting conditions, and may not physically be completely representative of the cutting process. Their accuracy is partially linked to mathematical properties, such as their degrees of freedom. This may lead to incoherent values for coefficients, when too many parameters are included in model, due to local value sensitivities during mathematical identification. Nevertheless, the mechanistic approach is very practical, and attains in a simple manner objectives such as torque spindle determination, computation of tool or workpiece deflection, or obtaining vibration stability using a stability lobe method, for example.

The analytical models are penalised by the large number of influential factors present in machining. The results obtained using these models can only partially represent the cutting process, due to necessarily simplified approaches. A model is often designed for one kind of work material, so that its transposition to another kind in- 


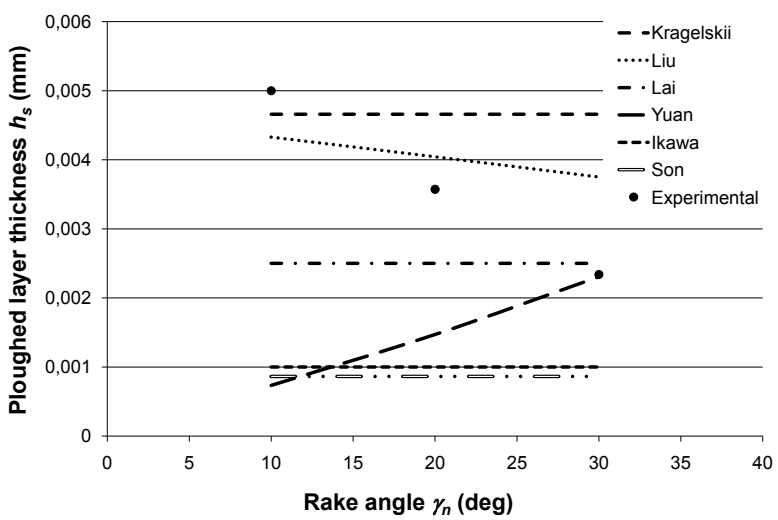

Figure 14: Comparison of ploughed layer depths

troduces discrepancies. Some models designed for conventional machining are not suitable for ultra precision machining, because of the modification of their slip line patterns due to edge geometry, for example. Nevertheless, the analytical models are essential to provide rapid access to physical quantities during cutting.

This work presents a review of different models and compares them for the case of pure copper. It shows the difficulty of reproducing ductile metal cutting, which may involve intensive metal sticking and a greater ploughing effect than in common steel machining. Thus it appears that a single model can not be applicable to all workmaterials, tools and cutting conditions with high precision. The accuracy of a cutting force model would be effective if:

- it duly considered essential parameters and phenomena,

- its formulation were adapted to the physical phenomena,

- its identification could be mathematically stable (uniqueness of the solution) and based on parameters which could be measured precisely.

To establish a model, major criteria, which engender significant effects on the cutting force, could be resume as follow:

- workmaterial properties: its plastic behavior (ductility or brittleness) is linked to the level of flow stress and the ploughing effect, 
- workmaterial / tool: friction behavior,

- tool geometry / cutting conditions: the effective cutting geometry with respect to uncut chip thickness.

Further studies on cutting force modelling should focus on phenomena which are currently often neglected. Workpiece contact with the tool clearance face, elastic recovery and workpiece radius (for example in internal turning) are often non-considered aspects. Similarly, the temperature and stress distribution on the tool still remain relevant objectives. In machining cases, the reaction of chemical additives from the cutting fluid affects the friction at the tool-chip interface. Thus, multiphysical modelling should be developed to get a better understanding of the cutting process in these conditions. These points may be largely involved in tool wear.

Most scientific contributions deal with orthogonal cutting, which is the basic configuration used to study the machining process. A future trend could be to develop the modelling method to move from orthogonal cutting to 3D cutting, completely taking into account local cutting parameters and geometries. This is of major interest for phenomenological and analytical models, which may lead to shorter computing times compared to numerical simulation.

\section{Acknowledgements}

The authors would like to thank the Burgundy Council and SNECMA for their financial support on projects related to force modelling.

\section{References}

Abdelmoneim, M.E., Scrutton, E.F., 1974. Tool edge roundness and stable build-up formation in finish machining. ASME Journal of Engineering for Industry $96 \mathrm{Ser}$ B, $1258-1267$.

Abdelmoneim, M.E., Scrutton, R.F., 1973. Post-machining plastic recovery and the law of abrasive wear. Wear 24, 1-13. 
Abdulaze, N.G., 1969. Character and the length of tool-chip contact. Machinability of heat resistant and titanium alloys. 68-78.

AFNOR, 1994. Domaine de fonctionnement des outils coupants - couple outil-matière.

Albrecht, P., 1960. New developments in the theory of metal cutting process: Part I the ploughing process in metal cutting. ASME Journal of Engineering for Industry $82,348-358$.

Armarego, E.J.A., Brown, R.H., 1969. The machining of metals. Prentice-Hall Englewood Cliffs, N.J.,.

Arsecularatne, J.A., Mathew, P., 2000. The Oxley modelling approach, its applications and future directions. Machining Science and Technology 4, 363-397.

Artozoul, J., Lescalier, C., D’Acunto, A., Bomont-Arzur, A., 2010. Stress and heat flux distribution in rake face analytical and experimental approaches. Proceeding of the 8th Conference on High Speed Machining, Metz, France , 6.

Barrow, G., Graham, W., Kurimoto, T., Leong, Y.F., 1982. Determination of rake face stress distribution in orthogonal machining. International Journal of Machine Tool Design and Research 22, 75-85.

Bissey, S., Poulachon, G., Lapujoulade, F., 2005. Modelling of tool geometry in prediction of cutting forces during milling of hard materials. Machining Science and Technology 9, 101-115.

Bitans, K., Brown, R.H., 1965. An investigation of the deformation in orthogonal cutting. International Journal of Machine Tool Design and Research 5, 155-165.

Bonnet, C., Valiorgue, F., Rech, J., Claudin, C., Hamdi, H., Bergheau, J.M., Gilles, P., 2008. Identification of a friction model - application to the context of dry cutting of an aisi 3161 austenitic stainless steel with a tin coated carbide tool. International Journal of Machine Tools and Manufacture 48, 1211-1223.

Boothroyd, G., Bailey, J.A., 1966. Effects of strain rate and temperature in orthogonal metal cutting. Journal Mechanical Engineering Science 8, 264-269. 
Budak, E., Altintas, Y., Armarego, E.J.A., 1996. Prediction of milling force coefficients from orthogonal cutting data. Journal of Manufacturing Science and Engineering $118,216-224$.

Cahuc, O., Darnis, P., Gérard, A., Battaglia, J.L., 2001. Experimental and analytical balance sheet in turning applications. International Journal of Advanced Manufacturing Technology 18, 648-656.

Challen, J.M., Oxley, P.L.B., 1984. Slip-line fields for explaining the mechanics of polishing and related processes. International Journal of Mechanical Sciences 26, 403-418.

Connolly, R., Rubenstein, C., 1968. The mechanics of continuous chip formation in orthogonal cutting. International Journal of Machine Tool Design and Research 8, 159-187.

Denkena, B., Tracht, K., Clausen, M., 2005. Predictability of milling forces based on specific cutting forces. Proceedings of the 8th CIRP Workshop on Modelling of Machining Operations,, Chemnitz, Germany , 259-266.

Dewhurst, P., 1978. On the non-uniqueness of the machining process. Proceedings of the Royal Society of London.A.Mathematical and Physical Sciences 360, 587-610.

Dudzinski, D., Molinari, A., 1997. A modelling of cutting for viscoplastic materials. International Journal of Mechanical Sciences 39, 369-389.

Enahoro, H.E., Oxley, P.L.B., 1966. Flow along tool-chip interface in orthogonal metal cutting. Journal Mechanical Engineering Science 8, 36-41.

Endres, W.J., DeVor, R.E., Kapoor, S.G., 1995. Dual-mechanism approach to the prediction of machining forces, Part 1: Model development. Journal of Engineering for Industry 117, 526-533.

Fang, N., 2003. Slip-line modelling of machining with a rounded-edge toolPart I: new model and theory. Journal of the Mechanics and Physics of Solids 51/4, 715-742. 
Fang, N., 2003. Slip-line modelling of machining with a rounded-edge toolPart II: analysis of the size effect and the shear strain-rate. Journal of the Mechanics and Physics of Solids 51/4, 743-762.

Germain, D., Fromentin, F., Poulachon, G., Bissey-Breton, S., 2010. A force model for superfinish turning of pure copper with rounded edge tools at low feed rate. Proceeding of the 8th Conference on High Speed Machining, Metz, France, 6.

Grunzweig, J., Longman, I.M., Petch, N.J., 1954. Calculations and measurements on wedge-indentation. Journal of the Mechanics and Physics of Solids 2, 81-88.

Günay, M., Aslan, E., Korkut, I., Seker, U., 2004. Investigation of the effect of rake angle on main cutting force. International Journal of Machine Tools and Manufacture 44, 953-959.

Hill, R., 1954. On the limits set by plastic yielding to the intensity of singularities of stress. Journal of the Mechanics and Physics of Solids 2, 278-285.

Ikawa, N., Shimada, S., Tanaka, H., Ohmori, G., 1991. An atomistic analysis of nanometric chip removal as affected by tool-work interaction in diamond turning. CIRP Annals - Manufacturing Technology 40, 551-554.

Jaspers, S.P.F.C., Dautzenberg, J.H., 2002. Material behaviour in metal cutting: strains, strain rates and temperatures in chip formation. Journal of Materials Processing Technology 121, 123-135.

Jawahir, I.S., Oxley, P.L.B., 1988. The tool restricted contact effect as a major influencing factor in chip breaking: an experimental analysis. CIRP Annals - Manufacturing Technology 37/1, 121-126.

Kapoor, S.G., Devor, R.E., Zhu, R., Gajjela, R., Parakkal, G., Smithey, D.W., 1998. Development of mechanistic models for the prediction of machining performance: Model-building methodology. Journal of Machining Science and Technology 22, 213-238. 
Karpat, Y., Özel, T., 2008. Mechanics of high speed cutting with curvilinear edge tools. International Journal of Machine Tools and Manufacture 48, 195-208.

Kato, S., Yamaguchi, K., Yamada, M., 1972. Stress distribution at the interface between tool and chip in machining. Transactions of the ASME Journal of Engineering for Industry 94, 683-689.

Kienzle, O., Victor, H., 1952. Die bestimmung von kräften und leistungen an spanenden werkzeugmaschinen. VDI-Z 94, 299-305.

Kline, W.A., DeVor, R.E., Lindberg, J.R., 1982. The prediction of cutting forces in end milling with application to cornering cuts. International Journal of Machine Tool Design and Research 22, 7-22.

Knüfermann, M.W., 2003. Machining Surfaces of Optical Quality by Hard Turning. $\mathrm{PhD}$ thesis. Cranfield University.

Ko, J.H., Cho, D.W., 2005. 3D ball-end milling force model using instantaneous cutting force coefficients. Journal of Manufacturing Science and Engineering 127, 1-12.

Kragelskii, I., 1965. Friction and wear. Butterworths.

Lai, X., Li, H., Li, C., Lin, Z., Ni, J., 2008. Modelling and analysis of micro scale milling considering size effect, micro cutter edge radius and minimum chip thickness. International Journal of Machine Tools and Manufacture 48, 1-14.

Lee, E.H., Shaffer, B.W., 1951. The theory of plasticity applied to a problem of machining. Trans. ASME, Journal of Applied Mechanics 18, 405-413.

Lee, H.U., Cho, D.W., Ehmann, K.F., 2008. A mechanistic model of cutting forces in micro-end-milling with cutting-condition-independent cutting force coefficients. Journal of Manufacturing Science and Engineering 130, 031102.

Liu, X., DeVor, R.E., Kapoor, S.G., 2006. An analytical model for the prediction of minimum chip thickness in micromachining. Journal of Manufacturing Science and Engineering 128, 474-481. 
L'Vov, N.P., 1969. Determining the minimum possible chip thickness. Machines \& Tooling (USSR) 40, 45-46.

Manjunathaiah, J., Endres, W.J., 2000. A new model and analysis of orthogonal machining with an edge-radiused tool. Journal of Manufacturing Science and Engineering 122, 384-390.

Marinov, V., 1999. The tool chip contact length on orthogonal metal cutting. Proceedings of International Conference on Advanced Engineering ant Technology.

Mesquita, R.M.D., Barata Marques, M.J.M., 1992. Effect of chip-breaker geometries on cutting forces. Journal of Materials Processing Technology, 31/1-2, 317-325.

Merchant, M.E., 1944. Basic mechanics of the metal cutting process. Journal of Applied Mechanics 11, A168-A175.

Molinari, A., Moufki, A., 2008. The Merchant's model of orthogonal cutting revisited: A new insight into the modelling of chip formation. International Journal of Mechanical Sciences 50, 124-131.

Moufki, A., Molinari, A., Dudzinski, D., 1998. Modelling of orthogonal cutting with a temperature dependent friction law. Journal of the Mechanics and Physics of Solids 46, 2103-2138.

Outeiro, J.C., Astakhov, V.P., 2005. The role of the relative tool sharpness in modelling of the cutting process. Proceedings of the 8th CIRP Workshop on Modelling of Machining Operations,, Chemnitz, Germany , 517-523.

Oxley, P.L.B., 1962. Shear angle solutions in orthogonal machining. International Journal of Machine Tool Design and Research 2, 219-229.

Oxley, P.L.B., 1998. Development and application of a predictive machining theory. Machining Science and Technology 2, 165-189.

Oxley, P.L.B., Hastings, W.F., 1977. Predicting the strain rate in the zone of intense shear in which the chip is formed in machining from the dynamic flow stress prop- 
erties of the work material and the cutting conditions. Proceedings of the Royal Society of London.A.Mathematical and Physical Sciences 356, 395-410.

Park, S., Kapoor, S.G., DeVor, R.E., 2004. Mechanistic cutting process calibration via microstructure-level finite element simulation model. Journal of Manufacturing Science and Engineering 126, 706-709.

Poletika, M.F., 1969. Contact loads on tool faces. Machinostronie

Pujana, J., Arrazola, P.J., M'Saoubi, R., Chandrasekaran, H., 2007. Analysis of the inverse identification of constitutive equations applied in orthogonal cutting process. International Journal of Machine Tools and Manufacture 47, 2153-2161.

Ranganath, S., Campbell, A.B., Gorkiewicz, D.W., 2007. A model to calibrate and predict forces in machining with honed cutting tools or inserts. International Journal of Machine Tools and Manufacture 47, 820-840.

Reddy, R.G., DeVor, R.E., Kapoor, S.G., 2001. A mechanistic force model for combined axial/radial contour turning. International Journal of Machine Tools and Manufacture 41, 1551-1572.

Reddy, R.G., Kapoor, S.G., DeVor, R.E., 2000. A mechanistic force model for contour turning. Journal of Manufacturing Science and Engineering 122, 398-405.

Rubenstein, C., 1990. The edge force components in oblique cutting. International Journal of Machine Tools and Manufacture 30, 141-149.

Saglam, H., Yaldiz, S., Unsacar, F., 2007. The effect of tool geometry and cutting speed on main cutting force and tool tip temperature. Materials \& Design 28, 101-111.

Sata, T., 1963. Recent developments concerning cutting mechanics. Proceedings of the International Production Engineering Research Conference, Pittsburg, USA. , $18-25$.

Shaw, M.C., 1982. A new approach to deformation zone analysis. International Journal of Machine Tool Design and Research 22, 215-226. 
Shaw, M.C., 1995. Precision finishing. CIRP Annals - Manufacturing Technology 44, 343-348.

Shaw, M.C., 2005. Metal Cutting Principles. Oxford university press edition.

Son, S.M., Lim, H.S., Ahn, J.H., 2005. Effects of the friction coefficient on the minimum cutting thickness in micro cutting. International Journal of Machine Tools and Manufacture 45, 529-535.

Stabler, G.V., 1951. The fundamental geometry of cutting tools. Proceedings of the Institution of Mechanical Engineers, London, UK 165, 14-21.

Stephenson, D.A., Bandyopadhyay, P., 1997. Process-independent force characterization for metal-cutting simulation. Journal of Engineering Materials and Technology $119,86-94$.

Stephenson, D.A., Jen, T.C., Lavine, A.S., 1997. Cutting tool temperatures in contour turning: transient analysis and experimental verification. Journal of Manufacturing Science and Engineering 119a/4, 494-501.

Stevenson, M.G., Oxley, P.L.B., 1970. An experimental investigation of the influence of speed and scale on the strain-rate in a zone of intense plastic deformation. Proceedings of the Institution of Mechanical Engineers, London, UK 184, 561-576.

Sutter, G., Molinari, A., 2005. Analysis of the cutting force components and friction in high speed machining. Journal of Manufacturing Science and Engineering, 127/2, $245-250$.

Thomsen, E.G., Yang, C.T., Kobayashi, S., 1965. Mechanics of plastic deformation in metal processing. Macmillan, Collier-Macmillan (New York, Toronto).

Toropov, A., Ko, S.L., 2003. Prediction of tool-chip contact length using a new slipline solution for orthogonal cutting. International Journal of Machine Tools and Manufacture 43, 1209-1215. 
Vogler, M.P., Kapoor, S.G., DeVor, R.E., 2004. On the modelling and analysis of machining performance in micro-endmilling, Part II: Cutting force prediction. Journal of Manufacturing Science and Engineering 126, 695-705.

Waldorf, D.J., DeVor, R.E., Kapoor, S.G., 1999. An evaluation of ploughing models for orthogonal machining. Journal of Manufacturing Science and Engineering 121, $550-558$.

Woon, K.S., Rahman, M., Neo, K.S., Liu, K., 2008. The effect of tool edge radius on the contact phenomenon of tool-based micromachining. International Journal of Machine Tools and Manufacture 48, 1395-1407.

Wu, D.W., 1988. Application of a comprehensive dynamic cutting force model to orthogonal wave-generating processes. International Journal of Mechanical Sciences $30,581-600$.

Yuan, Z.J., Zhou, M., Dong, S., 1996. Effect of diamond tool sharpness on minimum cutting thickness and cutting surface integrity in ultraprecision machining. Journal of Materials Processing Technology 62, 327-330.

Zhang, H.T., Liu, P.D., Hu, R.S., 1991. A three zone model and solution of shear angle in orthogonal machining. Wear 143, 29-43.

Zorev, N.N., 1966. Metal Cutting Mechanics. Oxford : Pergamon press edition.

Zvorykin, K.A., 1893. Work and stress necessary for separation of metal chips. Proceedings of the Kharkov Technological Institute, Ukraine . 